\title{
Stakeholders' Perceptions of Special Educator Induction Programs in a Low Attrition District
}

Jeremy Vittek

West Virginia University

Follow this and additional works at: https://researchrepository.wvu.edu/etd

\section{Recommended Citation}

Vittek, Jeremy, "Stakeholders' Perceptions of Special Educator Induction Programs in a Low Attrition District" (2012). Graduate Theses, Dissertations, and Problem Reports. 3593.

https://researchrepository.wvu.edu/etd/3593

This Dissertation is protected by copyright and/or related rights. It has been brought to you by the The Research Repository @ WVU with permission from the rights-holder(s). You are free to use this Dissertation in any way that is permitted by the copyright and related rights legislation that applies to your use. For other uses you must obtain permission from the rights-holder(s) directly, unless additional rights are indicated by a Creative Commons license in the record and/ or on the work itself. This Dissertation has been accepted for inclusion in WVU Graduate Theses, Dissertations, and Problem Reports collection by an authorized administrator of The Research Repository @ WVU.

For more information, please contact researchrepository@mail.wvu.edu. 
Stakeholders' Perceptions of Special Educator Induction Programs in a Low Attrition District

$$
\text { Jeremy Vittek }
$$

Dissertation submitted to the College of Human Resources and Education at West Virginia University in partial fulfillment of the requirements for the degree of

\author{
Doctor of Education \\ in \\ Special Education
}

Kim K. Floyd, Ph.D., Chair Barbara L. Ludlow, Ed.D. Richard T. Walls, Ph.D. Sharon B. Hayes, Ph.D. Melissa D. Hartley, Ph.D.

Keywords: Special Education; Induction; Mentoring; Retention Copyright 2012 Jeremy E. Vittek 


\section{Abstract \\ Stakeholders' Perceptions of Special Educator Induction Programs in a Low Attrition District}

\section{Jeremy E. Vittek}

Special education teacher attrition is a growing problem in the United States (Payne, 2005). Without proper induction for early career special educators, the potential remains for these educators to leave the field at a rate twice that of their general education counterparts (Payne, 2005). The lack of a defined national or state policy on induction programs puts the responsibility on the school district to design and implement an induction program. The goal of the study was to provide empirical insight into the stakeholders' perceptions of the challenges and supports provided for beginning special educators in a low attrition district within West Virginia through qualitative research methods. Two triads were recruited to participate in this study, each consisting of a beginning special educator, their mentor, and building administrator. Interviews and an observation were used to gather data. The findings from this study were the perceived need for varied supports for beginning special educators, the special education coordinator as the main source of support, and the perceived role of induction in special educator retention. Based on the findings from this study, future research could examine the role of e-mentoring, district level support, and the role induction plays on teacher retention. 


\section{Acknowledgements}

I am eternally indebted to many people who have helped me complete this program. I am thankful to Dr. Kim Floyd for her tireless work and guidance. She always had time to meet with me and provide suggestions and revisions that both challenged and helped me. Throughout my time as a student she filled a variety of roles, instructor, advisor, chair, mentor, and friend. Also, without Dr. Barbara Ludlow none of this would have been possible. I will always appreciate the opportunity and guidance she provided.

I would also like to thank the other doctoral students in this program. They provided me with motivation, guidance, advice, and friendship. There were times when I questioned myself throughout this program and there was always someone there to pick me up.

I have been blessed with a family that has constantly provided me with support. Without my mother and father I would not be in education, and I would not have had the motivation and confidence to pursue this opportunity. I also appreciate the support my brother and sister have provided. I love you all.

This has been an amazing experience and I would like to thank everyone who had a part in my success, including but not limited to all my instructors, the entire special education department, and everyone who has gone out of there way to help me earn my Ed. D. 


\section{TABLE OF CONTENTS}

Page

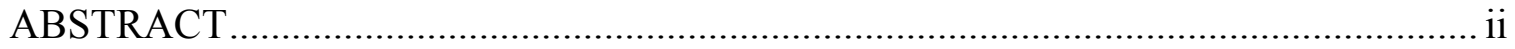

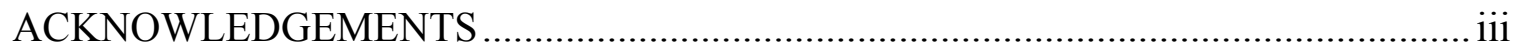

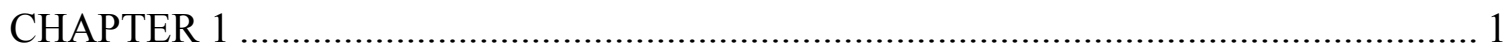

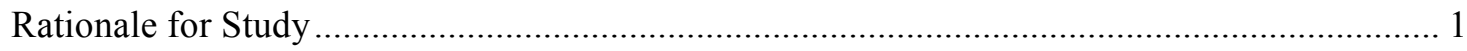

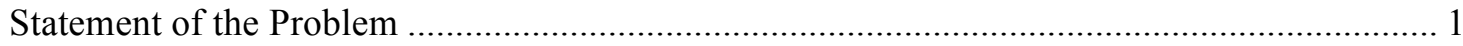

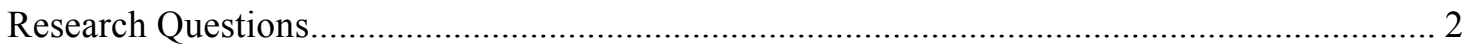

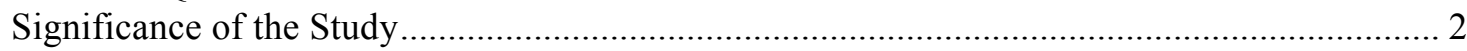

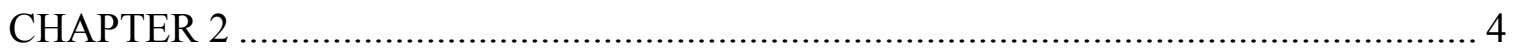

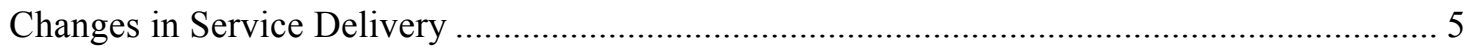

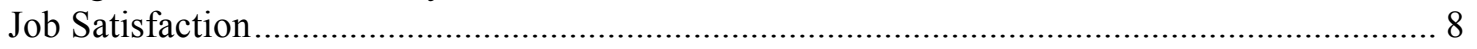

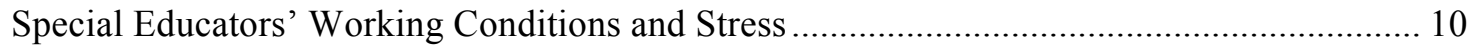

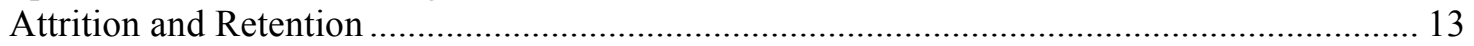

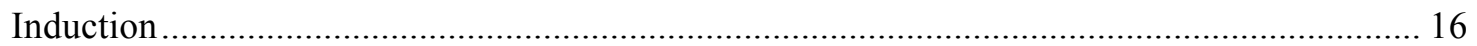

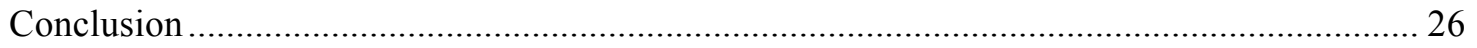

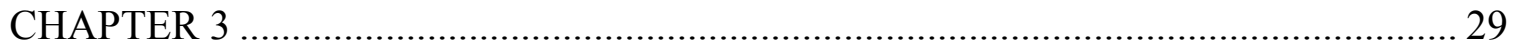

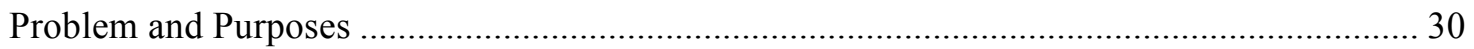

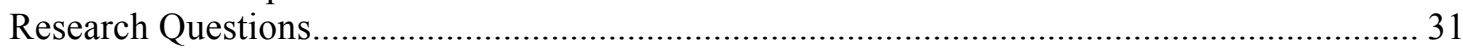

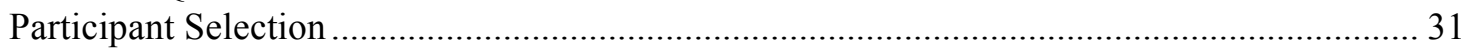

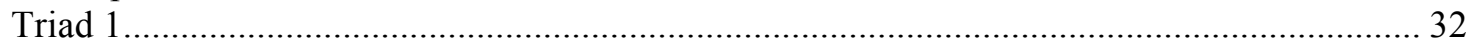

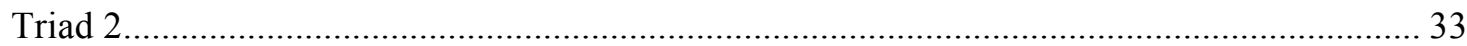

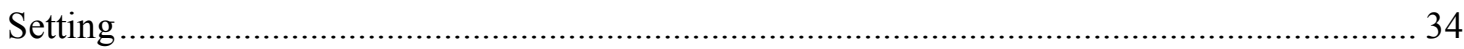

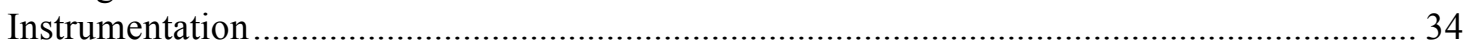

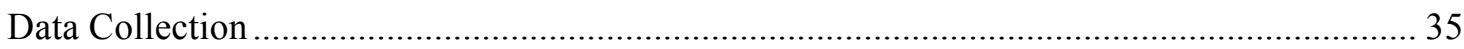

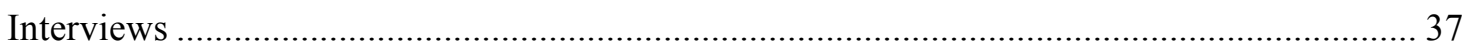

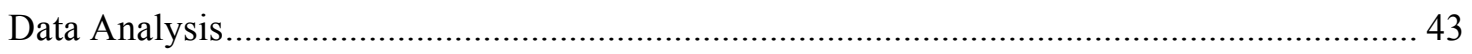

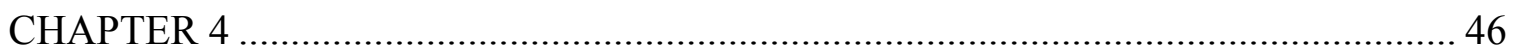

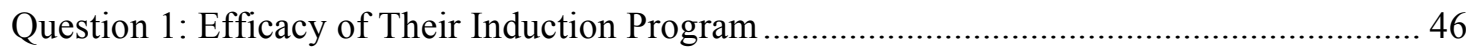

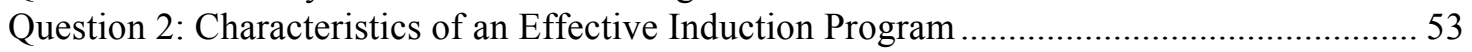

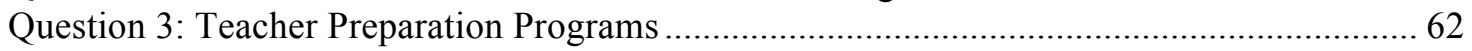

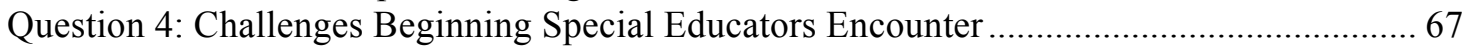

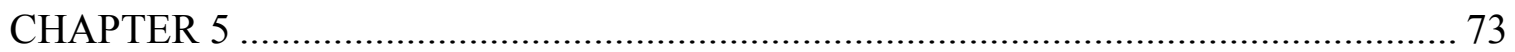

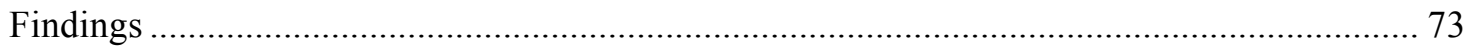

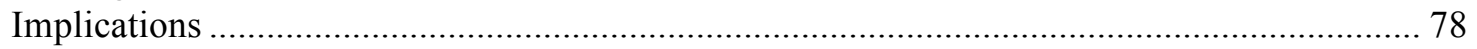

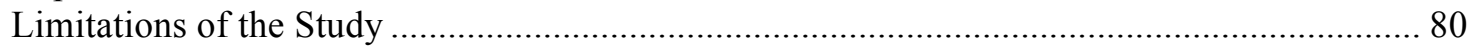

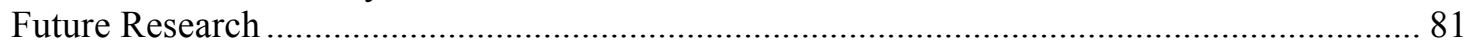

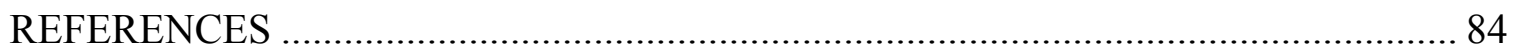

\section{APPENDICES}

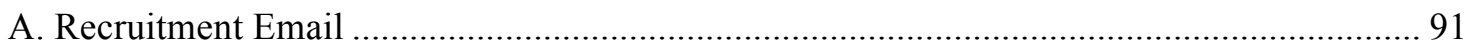

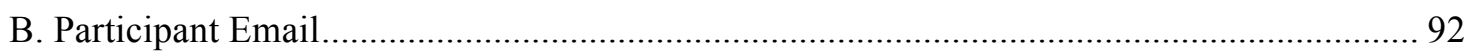

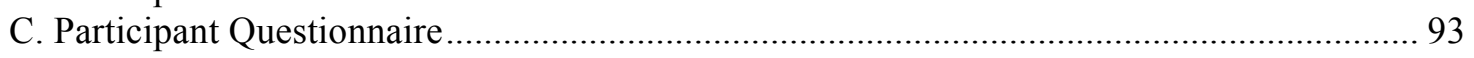

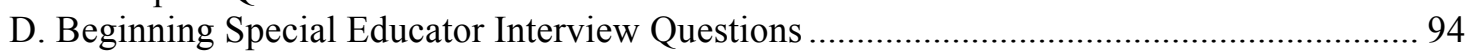

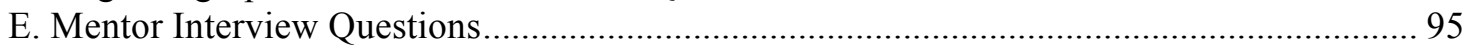

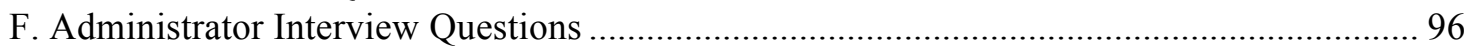




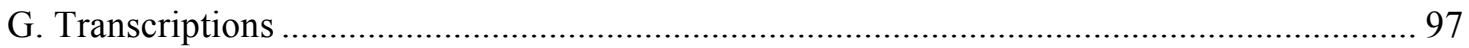

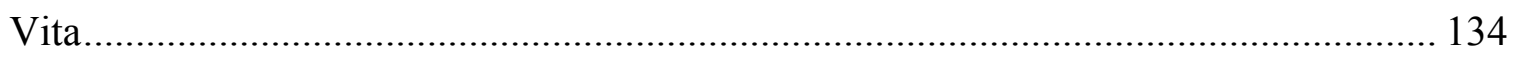




\section{CHAPTER 1}

There is a shortage of special educators in the United States. A large factor is the growing rate of attrition among special educators, particularly in the first five years of their career. Researchers have studied many potential strategies to assist with reducing the special educator attrition rate. A comprehensive, reflexive, special education-specific induction program has been shown to improve retention rates among special educators (Billingsley, 2004a; Wasburn-Moses, 2006).

\section{Rationale for Study}

This study is important because it will provide information useful in designing a special education induction program that addresses the research to practice gap, and this study may provide a starting point to bridge that gap. While a majority of the studies are quantitative, the findings will provide an in-depth description of what stakeholders consider to be the main stressors of early career special educators and the strategies to help alleviate these stressors.

\section{Statement of the Problem}

Special education teacher attrition is a growing problem in The United States (Payne, 2005). Stress is a prominent reason given for leaving the field early (Billingsley, 2007). There is empirical support for induction programs as a means for increasing retention by reducing stress (Billingsley, 2004a; Wasburn-Moses, 2006). However, induction programs must be strategically designed in order to meet the unique needs of special educators. A quality induction program for early career special educators should contain mentoring (Schlichte, Yssel, \& Merbler 2005), stress coping strategies (Cooley \& 
Yavenoff, 1996), and help for the early career special educator to integrate into the school environment (Billingsley, Carlson, \& Klein, 2004). Unfortunately, many induction programs do not employ these evidence-based practices. The lack of a defined national or state policy on induction programs puts the responsibility on the school district to design and implement an induction program. Without proper induction for early career special educators, the potential remains for these educators to leave the field at a rate twice that of their general education counterparts (Payne, 2005). With the high attrition rate of special educators it leaves many positions to be filled by uncertified teachers, which harms student outcomes.

\section{Research Questions}

This study is designed to answer the following research questions:

1. What are stakeholders' perceptions of the efficacy of their induction program?

2. What are stakeholders' perceptions of characteristics of an effective induction program?

3. What are stakeholders' perceptions of how teacher preparation programs prepare special educators for the challenges of being a beginning teacher?

4. What are stakeholder's perceptions of the challenges beginning special educators encounter?

\section{Significance of the Study}

The researcher aims to contribute to the growing literature regarding supports provided for beginning special educators by focusing on stakeholders' perception of their induction program. Also, there are only a few qualitative studies on this topic utilizing a case study method. The researcher hopes to provide data and findings that can be utilized 
to improve supports for beginning special educators. Many induction programs treat special and general educators as one, which often harms the efficacy of the program. Currently there is a research to practice gap, and the researcher aspires to contribute to the closing of this gap. 


\section{CHAPTER 2}

\section{Review of the Literature}

The roles and responsibilities of special educators have changed over time. These changes have caused varied working conditions. Currently, the differing roles and responsibilities have led to stress, burnout, and attrition among special educators. The high rate of special educator teacher attrition has led to a shortage in the field. There are several strategies that school districts have employed to support beginning special educators. A comprehensive, induction program specific to special education is needed to improve retention. The induction program should begin when the contract is signed, and continue until the educator is properly assimilated into the school culture. Retaining special educators is essential to providing students with disabilities with an effective learning environment.

The purpose of this literature review is to synthesize information and research on special education induction programs. In this chapter, literature is reviewed to determine how to best address the facets of a successful induction program. The following topics will be discussed (a) a brief description of the literature on the evolution of legislation in special education and the impact that has on the working requirements and stress of beginning special educators (b) a summary of the literature on the factors that lead to attrition and retention among beginning special educators. (c) the literature on induction programs in education was reviewed to identify the components of a successful special education induction program. (d) a summary of the research is presented to identify the need for special education induction programs, and the impact that has on retention. 


\section{Changes in Service Delivery}

The 1960's brought about drastic change in the service of students with disabilities. With help from the passage of the Education of Mentally Retarded Children Act of 1958 (PL 85-926) and Brown v. Board of Education ruling, special education advocacy groups gained traction in their quest to secure education for all children with disabilities. Local and state agencies began providing services, and in 1975, the federal government responded with the Education for All Handicapped Children Act (PL 94142). This act required all schools receiving federal funds to provide children with disabilities an education, as well as an education plan based on their specific disability. The result of this act was more than one million students with disabilities entering the public school system. This prompted the need for trained educators to provide the mandated services.

Upon entering the field of special education, teachers were given a wide variety of responsibilities. During the late 1960's and early 1970's the belief was held that children with disabilities were best served in self-contained classrooms. Additionally, special educators had to be proficient in the special programs needed to provide educational services to children with varying disabilities (Hoover \& Patton, 2008) due to the fact that students with varying disabilities were educated in a self-contained classroom. Thereby, the ability to teach multiple content areas was a necessity. Dunn's (1968) work spawned a new way of thinking regarding the delivery of services for children with disabilities. This seminal piece of work provided an argument that self-contained classrooms fostered segregation. His work led to many leaders in the field questioning the system. This 
guided a movement toward including students with disabilities in general education classes as much as possible.

The placements of students with disabilities shifted from self-contained classrooms to educating them in the general education classroom with help from the special educator, while being pulled out for help in areas of need. Educators realized the importance of finding the students' specific disabilities, and designing strategies to help them realize their potential (Hoover \& Patton, 2008). Further, the roles and responsibilities of special educators were redefined due to this mind shift. Special educators roles changed drastically due to the evolving legislation, as well as the advocating from leaders in the field.

The required skills of the special educator changed drastically as a result of the paradigm shift. As the delivery model changed, so did the type of instruction. Instead of delivering the content, as done in previous practice, special educators had to provide remediation for specific problems the students encountered. Further, the integration of students with disabilities into general education classrooms brought about the need for collaboration. In order to provide high quality instruction, general educators and special educators had to work closely to design the educational program for each student with a disability, a new skill that many educators had to acquire on the job.

The push toward mainstreaming continued into the 1980's. Special educators held similar responsibilities as they did in the 1970's. They were required to provide some direct instruction, and also design programs for the general educator. With more students with disabilities being educated in the general education classroom, special educators played a larger role in providing instructional strategies to the general educator. 
The mainstreaming initiative led to the process of inclusion. Although the term "inclusion" is not in special education law, the Individuals with Disabilities Education Act (IDEA) in 2004 required students with disabilities to be educated in the least restrictive environment to meet their unique needs. Mainstreaming was based on the belief that students with disabilities would benefit from being in class with their typically developing peers. Inclusion takes that belief a step further. The belief behind inclusion is children with disabilities have the right to be in the general education classroom, and learn alongside their peers.

With the movement toward inclusion, more students with disabilities were being educated in the general education classroom. In 1988 only $30 \%$ of the population of students requiring an IEP were educated in the general education classroom (U.S. Department of Education, 2011). However, this number has risen drastically over the past 20 years. Currently $58 \%$ of students with disabilities were educated in the general education classroom, while receiving services outside the classroom less than $21 \%$ of the school day.

Along with changes in service delivery models, special educators' roles have changed. Over the years their roles have evolved from teaching in a self-contained classroom, to providing support for general educators, to co-teaching with general educators. One of the challenging aspects of this model is the variety of co-teaching strategies a special educator may have to master. The special educator may take on several different roles as a co-teacher. They may be asked to observe the students while the general educator teaches, teach the lesson to the whole class, teach the lesson to a portion of the class, or provide support while the general educator teaches the lesson 
(Friend, Cook, Hurley-Chamberlain, \& Shamberger, 2010). Along with the variety of classroom roles, paperwork became a large portion of their workday. Vannest and HaganBurke (2009) found special educators spend $40 \%$ of their day on non-instructional tasks. The variety of responsibilities can lead to role confusion, which is one of the leading causes of stress among special education teachers. The factors that lead to stress determine the level of job satisfaction a special educator experiences. When that level is too low, they often contemplate leaving their position.

\section{Job Satisfaction}

The level of job satisfaction a teacher experiences can affect whether a teacher stays in special education, or moves to a general education position, or leaves the field of education all together (Gehrke \& McCoy, 2007). Many factors directly contribute to job satisfaction (e.g., administrative support, stress, and workload). First-year special educators encounter a variety of stressors. A workload that contains students with a variety of different needs, not enough planning time, paperwork, and current policy are several of the factors that provide stress, and lower job satisfaction (Plash \& Piotrowski, 2006). In a study conducted by Stempien and Loeb (2002) special educators rated themselves lower in overall job satisfaction than their general education counterparts. According to a case study by Billingsley (2007), teachers who left the field cited lack of support from parents and administrators, too much paperwork, limited availability of resources, and large class size as the main items that caused dissatisfaction. In a survey of 57 special educators that stayed in the field, Fish and Stephens (2010) found that a teacher's ability to serve his/her students leads to high job satisfaction, which increases the likelihood the teacher will stay in the field. 
Special educators are often required to complete work outside of what is asked of general education teachers, without additional compensation (Thornton, Peltier, \& Medina, 2007). This added responsibility is viewed as a hindrance on the teacher's ability to properly teach the class (Kaff, 2004; White \& Mason, 2006). Kaff (2004) used content analysis to examine the results of 341 questionnaires, deducing that instructional delivery is no longer the main role of special education teachers. However, special educators choose the field, and stay in it in order to teach and provide services for their students (Kaff, 2004). When they are stripped of this role, it leads to lower job satisfaction, and ultimately leaving the field. Consequently, Wasburn-Moses (2006) surveyed in-service and pre-service special education teachers to determine the role expectations of each. The researchers concluded pre-service teachers had an accurate expectation of the problems that they may encounter in their first year. However, the preservice teachers viewed their future role as one that is in line with current policy, while practicing teachers described far different roles. Special educator's roles can range from those of a classroom teacher to an educational consultant. Special educators also fill other roles out of necessity including the management of problem behaviors and the administering of social and vocational skills (Conderman \& Katsiyannis, 2002). This confusion of roles can lead to early stress and burnout because a teacher entering the field expects a certain role, but may be presented with something vastly different (WasburnMoses, 2006; Thornton et al., 2007). Beginning special educators face unique challenges that often cause stress. Prolonged periods of stress can lead to burnout, which impacts a special educator's intent to stay in their position, transfer to a general education position, or leave the field of education. According to researchers, the leading causes of stress for 
beginning special educators are: large workloads, lack of administrative support, lack of proper professional development, and role ambiguity (Plash \& Piotrowski, 2006).

Boe, Barkanic, and Leow (1999) found special education teacher attrition and retention are directly tied to administrative support. Boe and colleagues (1999) found educators who remain in their position view their administrators as supportive four times as much when compared to those educators who leave their positions. Administrators who provide emotional support are more likely to retain their special educators. Conversely, when there is a lack of emotional support, beginning special educators are more likely to experience burnout and ultimately leave their position. Another example of lack of administrative support is the absence of a proper induction program and professional development. Without the support provided from induction and professional development the beginning special educator often experiences extreme stress, and low job satisfaction. Stress and low job satisfaction result in teacher burnout, and ultimately attrition.

\section{Special Educators' Working Conditions and Stress}

In addition to role confusion and paperwork, the attitudes of general educators have an impact on the efficacy of co-teaching. Many general educators are not prepared to utilize the co-teaching model. Snyder (1999) postulated the need for better preparation for general educators. She felt the lack of preparation in inclusion strategies led to the negative attitudes general educators sometimes possess. These attitudes cause feelings of resentment and detract from the educational environment. Hammond and Ingalls (2003) surveyed rural teachers and found overwhelming frustration toward inclusion due to the lack of preparation in inclusion, and limited support to properly employ the effective 
strategies. Van Reusen, Shoho, and Barker (2000) found a correlation between general educators' special education training and positive attitudes toward inclusion. Along with proper preparation, administrators must provide support for co-teaching to be effective.

Lack of administrative support is a direct cause of stress for special educators (Schlichte, Yssel, \& Merbler, 2005). Special educators are in a difficult position because their role in the co-teaching relationship is often viewed as the secondary teacher or assistant to the general educator (Keefe \& Moore, 2004). There is a struggle for equality, which is exacerbated by the lack of support from the building principal. In order for coteaching to be effective, each teacher must know his or her role and be properly supported by the principal. Praisner (2003) surveyed principals and found their special education training plays a large role in their attitude toward inclusion. Those who had targeted training in special education had a more positive attitude toward inclusion. These principals were more aware of the characteristics of students with disabilities, the strategies to educate them, and special education law. When a principal was educated in these three areas they often understand the importance of inclusion, and the impact they have on its efficacy. Principals play an essential role in special educators' stress. If the principal provided proper support for their special educators, the special educators' stress level would be manageable. However, when proper support is not provided, special educators experience higher levels of stress, and there is a higher potential they leave their position.

Further, administrators often fail to provide their special educators with adequate planning time. In the inclusion model, planning time is one of the most important aspects to ensure efficacy (Friend et al., 2010). The general educator and special educator must 
have planning time together in order to design their lessons. Horne and Timmons (2009) conducted a qualitative study of teachers' perceptions of inclusion. The findings from this study provided supports for prior research, citing inadequate planning time as one of the main downfalls of inclusion. Special educators must have an opportunity to collaborate with the general educator; to educate their colleague on instructional and behavioral strategies need to reach the children with special needs, and to agree upon the design of their co-teaching instruction/design. When there is not enough time to adequately design co-teaching strategies they will utilize, the general educator often takes the lead. This lack of time and opportunity to collaboratively approach the classroom instruction contributes to the previously discussed role confusion, stress, and ultimately attrition.

The combination of role confusion, lack of administrative support, and inadequate planning time can result in a poor school climate. Gersten, Keating, Yovanoff, and Harniss (2001) found the overall school climate had a strong impact on a special educators' intent to stay or leave the field. The school climate is set from the district administration down to the building principal. A school district that does not embrace inclusion practices and provide support will have a poor school climate (Dyal, Flynt, \& Bennett-Walker, 1996). When there is not a clear vision of how inclusion will be incorporated, a variety of strategies will be employed. This often leads to confusion, and poor student outcomes (Dyal et al., 1996). A positive school climate starts at the top and permeates down to each person in the district. The district administrators must promote inclusion as, not only, what law requires, but also what is moral. Next, the district must provide professional development to educate the school personnel on the different roles 
and strategies in co-teaching (Friend et al., 2010). Once the roles and guidelines are clear, general educators and special educators can begin to collaborate on teaching strategies. This process will not make every person in the district agree with inclusion, but it may provide the best opportunity for a positive school climate.

Special educators are often given the most difficult assignment upon entering a

district. Due to the shortage of qualified special educators, districts frequently assign the beginning special educator a large caseload. The added strain on an already stressful situation can cause teacher burnout (Gersten, Keating, Yovanoff, \& Harniss, 2001). This stressor can be alleviated by proper support from the building level administrator.

\section{Attrition and Retention}

The varied roles and unique stressors of special educators coupled with a lack of support, often results in attrition. According to Plash and Piotrowski (2006), 13.2\% of special educators leave their positions each year. In rural districts, the rate can be as high as double (Plash \& Piotrowski, 2006). Special educators are at a greater risk to leave their positions within the first five years (Billingsley, Carlson, \& Klein, 2004). Early career special educators leave the field because of low job satisfaction caused by a variety of factors (Billingsley, 2007). The increasing rate of special educator attrition, along with the growing need for highly qualified special educators has led to a shortage in the field (Boe \& Cook, 2006).

The shortage of qualified special educators creates negative outcomes for students (Darling-Hammond \& Sclan, 1996). Researchers cite various reasons for the shortage, with attrition being the most prominent (Billingsley, 2007; Katsiyannis, Zhang, \& Conroy, 2003; Leko \& Smith, 2010). Often times they are placed in difficult settings due 
to the shortage of certified teachers (Feiman-Nemser, 2004). Difficult placements are compounded by a lack of administrative support (Nance \& Calabrese, 2009; Schlichte, Yssel \& Merbler, 2005). These factors cause higher stress levels and lower job satisfaction among special educators, when compared to their general education counterparts (Stempien \& Loeb, 2002). Uncertified teachers fill many vacant positions due to shortage of special educators, which has a negative impact on student achievement (Henry, Bastian, \& Fortner, 2011). In order to close the gap between special education positions and certified teachers, retention must increase.

Special educator attrition and retention is defined using a variety of terms. This document will use the terms outlined in Billingsley's (1993) review of the literature. If a special educator remains in the same position as the previous year it is called absolute retention (Boe, 1990). If a special educator stays in the field, but takes another position it is labeled, "transfers to another special education teaching position." When special educators transfer to general education positions it is called "transfers to general education teaching" (Billingsley, 1993). The final group, "exit attrition," is for special educators who leave the field of education. Although each group causes problems for the field of special education, exit attrition is the most serious outcome because it reduces the overall teacher workforce (Boe, Bobbit, Cook, Whitener, \& Weber, 1997).

Many variables and characteristics have been studied to determine their correlation with special education teacher attrition. Greiner and Smith (2009) examined 503 graduates of a Texas University and concluded variables such as standardized reading proficiency scores, undergraduate grade point average, gender, and ethnicity have no correlation with teacher attrition. Olivarez and Arnold (2006) surveyed 228 teachers 
in south Texas and determined the average special education teacher who remained in the field is Caucasian, has earned a Bachelor's degree, and is at least 30 years old. However, the researchers admit other characteristics must be cross-referenced in order to have predictive value relating to teacher retention. In another study, Elfers, Plecki, and Knapp (2006) examined attrition in Washington state, which found that a teacher's race has no bearing on whether he or he leaves or stays in the field. This research strengthens what Billingsley (2004a) concluded in that age is the only characteristic related to special education attrition. Age has shown a correlation due in large part to the majority of early-career special education teachers are younger in age, and many teachers generally leave the field early on in their career.

Early career special educators need a comprehensive and specific induction program to provide them with the necessary support. There is a gap between what the research suggest should be included in induction programs, and what many programs actually contain. Billingsley and colleagues (2004a) found that one third of early career special educators who responded to their survey did not find their formal induction program helpful. There is empirical support outlining the components of an effective induction program. Early career special educators require mentoring (Schlichte, Yssel, \& Merbler 2005), IEP assistance (Wasburn-Moses, 2006), professional development (Billingsley, 2004a), and help socially integrating into their new jobs (Billingsley et al., 2004). Special educators face a unique set of challenges, and need support in order to perform their job and remain in the field. These unique challenges require support from a formal Mentor, and support from the other school personnel the teacher must associate with. 


\section{Induction}

Induction programs began in the early 1980's and have evolved over time. Mentoring is a key component of a new teacher induction program. In order for the induction program to be effective it must provide an orientation component, mentoring, and administrative support.

History. New teacher induction and mentoring can be traced back to 1980, when Florida implemented the first state sponsored program in the United States. Before 1980 new teacher induction was usually an informal process designed by districts. In a survey of Ohio public school teachers, Compton (1979) found beginning teachers received little to no guidance, and were expected to be able to do the job upon entering the building. Since 1980 mentoring has become an integral part of induction programs. Fagan and Walter (1982) pontificated the need for an induction program in education much like those in other professions. They surveyed a group of educators, police officers, and nurses. Their findings showed educators were mentored at about the same rate as the other professions, but the perception of educators was their mentoring was not as beneficial. In the early 1980's mentoring became a buzzword in education, and the thought was it would help integrate new teachers into the school (Gehrke \& McCoy, 2007). In this time period, mentoring and induction are used interchangeably. However, mentoring programs are often implemented without considering research-based practices. This leads to a mentoring program that is not as beneficial to new teachers as it could be. Policymakers believed mentoring was a valuable strategy to provide support for new teachers on location (Onchwari, \& Keengwe, 2008). Currently more than 30 states require some form of mentoring for new teachers. 
The Council for Exceptional Children (CEC) (1997) outlined six guidelines for mentoring programs of new special educators:

1. The objectives of the Mentoring Program, its purposes and options, are clear and have been agreed upon by beginning teachers, experienced Mentors, and representatives from district and building administrators.

2. Information concerning roles, expectations, policies, provisions, and desired outcomes of the Mentoring Program is readily available and shared with beginning teachers, mentors, and administrators.

3. The Mentoring Program is planned and adequately funded.

4. All first year teachers are expected to participate in the Mentoring Program.

5. Mentoring for special education teachers may be coordinated with other, more general, mentoring programs within the school district, but must specifically address those issues unique to special education.

6. The Mentoring Program is designed to provide assistance and support only and is not related to any formal evaluations, certification requirements, or reemployment issues.

The CEC has provided principles and guidelines for a mentoring induction program. However, West Virginia Policy 5900 is the state policy that requires a mentoring induction program. This policy does not distinguish between general and special educators. Policy 5900 provides an outline of a basic mentoring program, allowing for collaboration and meetings between the Mentor and beginning teacher "when possible." West Virginia requires a teacher have five years of experience, with three coming in the 
county they will be a Mentor. The teacher must attend a two-part, four-day training program in order to obtain the Mentor certificate. A Mentor is paid a yearly stipend of $\$ 600$. Although the state policy requires an "experienced classroom teacher at the school who teaches the same or similar subject and grade level as the beginning teacher (if possible), and who shall serve as a Mentor for the beginning teacher," this can be interpreted in many ways. Weimer (2011) found that over half (57\%) of West Virginia districts do not require the Mentor teach the same subject as the mentee. Conversely, only 11 of $28(39 \%)$ respondents required the Mentor teach the same subject as the mentee.

The No Child Left Behind Act of 2001 (NCLB) outlines several strategies to improve teacher quality. One of the strategies is a new teacher induction program. There is no outline for the program or specific guidelines for inducting new special educators opposed to new general educators. According Holdman and Harris (2003), special educators provide different answers than general educators when asked about what they value in an induction program. The Council for Exceptional Children (CEC) adopted standards for new special educators (CEC, 1997). The standards suggested at least one year of an induction program, which included mentoring from an experienced teacher who holds a position in special education. The CEC suggests mentors are chosen based on experience and role. However, West Virginia does not pair Mentors with mentees based on the same criteria. Weimer (2011) found that 57\% of West Virginia districts do not require the Mentor teach the same subject as the mentee. Conversely, 39\% of the respondents required the Mentor teach the same subject as the mentee. In West Virginia, there is no distinction between the induction program for general educators and special 
educators, and further, Mentors are often paired with mentees based on seniority, rather than role similarity.

Components. Induction programs can be made up of different components, but certain aspects are required for effectiveness. Induction programs must be a sustained program that provides information and support for the individual needs of special educators (Billingsley, 2004a). Serpell (2000) defined induction as a process that, "begins with the signing of a contract, continues through orientation, and moves toward establishing the teacher as a professional" (p. 3). A major component of a successful induction program is a mentoring program. The success of a mentoring program is predicated on a Mentor that provides quality advice to the young teacher as well as a good listener (Schlichte, Yssel, \& Merbler, 2005).

Researchers have found that a comprehensive, special education-specific induction program is necessary to properly support early career special educators (Wasburn-Moses, 2006). The induction program can provide early career special educators with the necessary support to keep them in the field, and improve their teaching skills. Henry, Bastian, and Fortner (2011) found uncertified teachers have a negative impact on student outcomes. This shows the importance of retention on student results. Special educators leave their positions at a higher rate than their general education counterparts (Prater, Harris, \& Fisher, 2007). The attrition rate of special educators is higher in rural areas compared to urban areas (Katsiyannis, Zhang, \& Conroy, 2003). This revolving door on the classroom leaves students with uncertified or beginning teachers every year; they never experience the benefits of a veteran teacher. School 
districts utilize a variety of strategies to retain special educators and to help improve their teaching skills. These strategies are contained within an induction program.

A comprehensive, reflexive induction program for special educators must contain ongoing supports (Leko \& Smith, 2010). According to Irinaga-Bistolas, Schalock, Marvin, and Beck (2007) the program should have an orientation, professional development, and mentoring. The program should allow the special educator to adjust to the school climate, while improving their pedagogical skills (Wasburn-Moses, 2006).

The orientation portion of the induction program should begin as soon as the special educator signs their contract. At this point, the district should assign a Mentor to the beginning teacher. The Mentor, along with district administrators should hold an orientation session for the beginning special educators. The district should provide any written materials necessary to help the beginning teacher acclimate themselves to the school district.

The individualized education program (IEP) process differs slightly on the district and state levels. Teacher preparation programs train teachers to write and implement IEP's, but some teachers are trained in a different state from where they teach. These factors may cause stress for new teachers, which would require additional training. An induction program should contain IEP training in order to help the new teacher learn the nuances of the state and district they teach in. In addition, the Mentor will begin to provide emotional support to help prepare the beginning teacher for the start of the school year.

Another important strategy school districts use is mentoring. Mentoring is an important component to ensure the success of early career special educators (Brownell, 
Hirsch, \& Seo, 2004). Billingsley, Carlson, and Klein (2004) found beginning special educators consider their fellow teachers as their best support system. Pairing a Mentor with a mentee is a delicate and important process (Whitaker, 2000). Ideally, the Mentors would have at least three years experience and hold a similar teaching assignment to the mentee. The Mentor should possess good listening skills, and the ability to provide timely advice for specific problems the mentee may experience (Amos, 2005). However, finding the appropriate Mentor is only part of the process. The school district must provide the Mentor with the needed resources.

Administrators must provide sufficient support to ensure an effective mentoring program (Irinaga-Bistolas, Schalock, Marvin, \& Beck, 2007). Due to the added responsibilities, Mentors need additional time away from their regular duties to conduct observations and meetings with their mentee. There is empirical support for the fostering of the Mentor mentee relationship (Jones \& Pauley, 2003). School districts often provide professional time for the Mentor and mentee to meet at the beginning of the year to work on developing a relationship. The Mentor provides support across all spectrums of teaching. After the initial meetings, Mentors and mentees should meet on a weekly basis.

The Mentor, given adequate time to prepare, should observe the early career special educator frequently. Early in the year, this can be as often as once a week. The Mentor should gather formative information, and not evaluate the early career special educator (Gehrke \& McCoy, 2007). This provides the Mentor with the opportunity to compile a list of strengths and weaknesses. The Mentor will refer to the list when devising interventions to help the mentee improve weak areas. The mentee can also observe the Mentor to see how they utilize different teaching strategies. Along with 
improving practice, helping beginning special educators negotiate the pitfalls they often face is an important part of their role.

Mentoring can take place in a formal or informal setting. Billingsley, Carlson, and Klein (2004) found first year teachers preferred and benefited most from informal mentoring. Informal mentoring may provide a first year educator with more problemspecific advice, rather than a predetermined formal mentoring program (Billinsgley, Carlson, \& Klein, 2004). There is research that supports the benefits of informal and formal mentoring programs. Although the findings differ, research supports the benefits of having a mentoring program and the positive effect it can have on teacher retention. Additionally, there is literature that indicates the mentoring should continue beyond the first year. Research findings indicate that special educators run the greatest risk of leaving in their first five years (Gehrke \& Murri, 2006; Katsiyannis et al., 2003). Additional years of mentoring would provide the mentee with guidance beyond their first year, and train them to someday be a Mentor. Providing a novice teacher with the proper mentoring will enhance their job satisfaction, their ability to perform their job, as well as improve the likelihood they will stay in their jobs (Brownell et al., 2004; Thornton et al., 2007).

A Mentor must provide their mentee with extensive guidance on national and state laws and the implications they have on district policies. The administrators should introduce this at the orientation, but Mentors must continue this support throughout the program. If the early career special educator was prepared in a different state, they may not have experience with the I.E.P. forms used in their district. The Mentor must aid the early career special educator in writing their I.E.P.'s to make sure they follow state and 
district guidelines (Wasburn-Moses, 2006). Along with specific support from their Mentor, early career special educators can benefit from other colleagues as well. Researchers have examined informal mentoring, and found it can be just as effective as formal mentoring (Billingsley, Carlson, \& Klein, 2004). Informal mentoring can come from natural relationships with other colleagues, or from a previously assigned support team.

Although mentoring is an important strategy to help improve and retain beginning special educators, the presence of a Mentor is not enough. The Mentor must be properly trained, give specific advice, and be a good listener. According to Serpell (2000), Mentors must be appropriately trained in order to promote effectiveness. Gehrke and McCoy (2007) found beginning teachers value a Mentor who is experienced in the same area they are teaching. This allows them to receive advice pertaining to their specific job. When a general educator is assigned as a Mentor for a beginning special educator there is a gap between the information the Mentor possesses and the information a beginning special educator may require. Proximity is also important, but not a necessity. Holdman and Harris (2003) discovered beginning teachers prefer a Mentor in their building, but that is not always possible. Rather than place a beginning special educator under the mentorship of a general educator, it is more beneficial to find a special education Mentor in a neighboring district (Holdman \& Harris, 2003). Smith and Israel (2010) purposed ementoring if a Mentor in the same field is not available at the beginning teacher's school. Smith and Israel (2010) define e-mentoring as, "the use of computer-mediated communications such as e-mail, discussion boards, chat rooms, blogs, Web conferencing, and growing Internet-based solutions that are changing the way Mentors and mentees 
interact" (p. 30). Once a Mentor is trained and, if necessary, certified their effectiveness relies on their ability as well as the program structure.

The support team allows the beginning teacher to have a variety of resources to call upon for specific problems (Billingsley, 2004a). Ideally, the support team would consist of the Mentor, a general education teacher, a special educator who recently completed the induction program, and the guidance counselor. The general education teacher is a valuable resource that can provide insight into the collaboration process. An early career special educator who recently completed the induction program can offer support based on their experiences in a similar situation. The school guidance counselor should be involved in the mentoring process because they are responsible for counseling not only the students but their colleagues as well. This is a part of counseling preparation programs, but is rarely utilized. The guidance counselor can be another person to confide in when the early career special educator is experiencing stress. Although the other members of the support team are assigned to the early career special educator, the interactions with the early career special educator are usually not scheduled, and thusly considered informal in nature. This support team can provide support as well as help provide professional development for the early career special educator.

Professional development is an important component to help early career special educators. Researcher has shown there is a significant correlation between effective professional development, improved teacher practices, and student outcomes (Billingsley, 2004a). In order to provide effective professional development district administrators must collaborate with beginning special educators to determine the focal point (Gersten, Keating, Yovanoff, \& Harniss, 2001). According to Billingsley (2004a) professional 
development should be designed to improve student outcomes. Mentors can help improve the teaching practices of beginning special educators, but professional development is also needed. Professional development provides an opportunity to beginning special educators to learn new teaching strategies, and how they can apply them to specific students on their caseload.

Professional development is provided for many teachers, but it is often the same for the entire staff. Early career special educators need professional development that is designed to help them navigate the pitfalls they will face in their first years (Boyer, 2005). Holdman and Harris (2003) examined Project Launch which is an induction program developed by the Bismarck-Mandan Area Teacher Center. The results of Project Launch were examined, and the findings suggested a need for a structured mentoring program and at least four all day in-services (Holdman \& Harris, 2003). New teachers have different issues arise throughout the school year. Providing them with daylong in-services throughout the year allows the induction program to adapt to the unique challenges of each individual.

The district should design the professional development in a way that provides a new teaching strategy in an easy to understand way (Gersten, Chard, \& Baker, 2000). Also, professional development should contain a detailed explanation about the reasoning behind the strategy. New teachers are hesitant to try recently learned strategies. However, if they are told why the strategy was designed, and about the research that backs it up, they are more apt to employ the strategy (Gersten, Chard, \& Baker, 2000). The beginning special educator will benefit from professional development that allows 
them to learn about a strategy and incorporate it in their classroom without additional instruction.

Administrative support is a factor in the efficacy of professional development. Professional development is often redundant and non-pertinent for beginning special educators. However, if administrators work in conjunction with the mentoring support team the professional development becomes more meaningful (Billingsley, 2004a). Utilizing this model allows specific professional development for beginning special educators, highlighting their unique needs. Beginning special educators are more likely to learn when the topic of the professional development is timely, pertinent, and easily accessible.

The roles and responsibilities of special educators have a large impact on the delivery of services to students with disabilities. These roles and responsibilities have changed drastically over the past 60 years. The roles and responsibilities of special educators are driven by the placement of students with disabilities. The students with disabilities were originally educated in self-contained classrooms, and now the majority are educated in general education classrooms. The differing skills needed by special educators has caused role confusion and stress, which leads to attrition. Districts employ a variety of strategies in order to curb attrition and improve student outcomes. These strategies range from orientation, to mentoring, and professional development, which are all combined within an induction program.

\section{Conclusion}

Since the inception of special education in public schools, the roles and responsibilities of special educators have evolved. As it stands, special educators have 
varied roles, and often take on a caseload larger than general educators. Along with a large caseload, they are required to complete paperwork without the benefit of extra time or compensation. These additional stressors cause the high rate of attrition among special educators. The attrition rate along with the growing need for special educators has resulted in a shortage. In order to alleviate the shortages, researchers have recommended induction and mentoring designed for special educators.

The literature on beginning special educator attrition and retention shows a need for a special education specific induction program (Billingsley, 2004a). The unique stressors beginning special educators encounter provide the need for an induction program designed to alleviate these issues. Induction programs have been shown to promote retention among special educators (Wasburn-Moses, 2006).

Although the literature shows a definite need for an induction program designed for special educators, there are no states that require such a program. Most states require an induction program, mentoring, or both for beginning teachers. However, there is no distinction between general and special education teachers.

There is a need for an induction program for special educators. Since there are no federal or state guidelines requiring such a program, there are varied opinions on what should make up the program. There is currently a gap in the research. This study aims to fill the gap on what stakeholders believe should be a part of an effective induction program for special educators. There is a paucity of qualitative studies on teacher retention and induction programs. The qualitative studies on this topic have dealt with the problems beginning special educators face, and what can be done to retain them. This study will aim to find the stakeholder's perceptions of the characteristics of effective 
induction programs for special educators. The study will also help to display the potential gap between research and practice. Although there are no clear guidelines for a special education specific induction programs, schools may employ one on their own. 


\section{CHAPTER 3}

\section{Methodology}

A qualitative method, multiple case study, was employed for this study due to the nature of the research questions. Qualitative research is utilized to study people's interactions with their settings, and the meanings derived from those interactions (Denzin \& Lincoln, 2005). One of the purposes of this study was to determine how people interact with their surroundings and examine the meaning they derive from those interactions which aligns with a social constructivist perspective. This specific qualitative method provided data to construct each individual's understanding of the phenomena and address each of my research questions.

Additionally, interpretivism, a theoretical perspective, rooted in the search to "understand and explain human and social reality" (Crotty, 2004, p. 66-67), also assisted in guiding the direction and focus of this study. Further, the design provided data to understand the participants as individuals and examine what their perceptions are of their induction program.

Participants were placed in triads. Each triad consisted of a beginning special educator, their Mentor, and their building level administrator. From the interview transcripts and observational notes, conventional content analysis was conducted to extract meaning from the transcriptions without tainting it. This phenomenological approach provided the opportunity to derive thoughts and meanings from a familiar environment in order to describe the induction program in richer detail than if another form of analysis was employed. Each triad was studied, and the themes of each were compared to determine if any findings could be drawn. 


\section{Problem and Purposes}

Special education teacher attrition is a growing problem in The United States (Payne, 2005). Stress is a prominent reason given for leaving the field early (Billingsley, 2007). There is empirical support for induction programs as a means for increasing retention by reducing stress (Billingsley, 2004a; Wasburn-Moses, 2006). However, induction programs must be strategically designed in order to meet the unique needs of special educators. A quality induction program for early career special educators should contain mentoring (Schlichte, Yssel, \& Merbler 2005), stress coping strategies (Cooley \& Yavenoff, 1996), and help for the early career special educator to integrate into the school environment (Billingsley, Carlson, \& Klein, 2004). Unfortunately, many induction programs do not employ these evidence-based practices. Without proper induction for early career special educators, the potential remains for these educators to leave the field at a rate twice that of their general education counterparts (Payne, 2005). With the high attrition rate of special educators it leaves many positions to be filled by uncertified teachers, which harms student outcomes.

The researcher aims to contribute to the growing literature regarding supports provided for beginning special educators by focusing on stakeholders' perception of their induction program. Also, there are only a few qualitative studies on this topic utilizing a case study method. The researcher hopes to provide data and findings that can be utilized to improve supports for beginning special educators. Many induction programs treat special and general educators as one, which often harms the efficacy of the program. Currently there is a research to practice gap and the researcher aspires to contribute to the body of literature that influences induction program development. 


\section{Research Questions}

The research questions that guided this study are: (1) What are stakeholders' perceptions on the efficacy of their induction program? (2) What are stakeholders' perceptions of characteristics of an effective induction program? (3) What are stakeholders' perceptions of how teacher preparation programs prepare special educators for the challenges of being a beginning teacher? (4) What are stakeholder's perceptions of the challenges beginning special educators encounter?

\section{Participant Selection}

Convenience sampling is a form of purposeful sampling which produces participants with the potential for rich information, while being easily reached by the researcher (Patton, 2002). Convenience sampling was used to identify a school district in West Virginia as the setting to search for possible participants.

An email was sent to the county's board office. After receiving written permission to conduct the study in that county, participant recruitment began. The special education coordinator forwarded the recruitment email (see Appendix A) to potential participants. Once two beginning teachers responded, their Mentors and administrators were contacted to request their participation. Both pairs of Mentors and administrators agreed to take part in the research study and the two sets of triads was created.

Participant qualifications. The beginning special educators held valid special education certification in West Virginia and were in their first year of teaching in a special education setting. The Mentors held valid special education certification, as well as valid mentoring certification in West Virginia. The administrators held a valid certificate in administration in West Virginia. 


\section{Triad 1}

Teacher 1. Teacher 1 serves gifted students in kindergarten through fifth grade. She also does homebound instruction and tutors students with autism. This is her first year in this position. She has a bachelor's degree in elementary education with a minor in multi-categorical special education and an autism endorsement.

Mentor 1. Mentor 1 currently serves as a special educator in sixth through eighth grade. Her classroom set up is self-contained and she provides services for students with multiple disabilities (MD), learning disabilities (LD), behavior disorders (BD), and Autism. This is her first year in this position. Prior to this year she taught gifted and students with learning disabilities for six years. She is certified in elementary education K-6, MI, LD, BD, Gifted, and Autism. She has a bachelor's plus 15 additional hours. This is her first year as a Mentor. She completed the Mentor training program to gain certification in mentoring. She was assigned to Teacher 1 because she previously held the position Teacher 1 currently holds.

Administrator 1. Administrator 1 is a middle school principal; this is her first year in this position. She has her bachelor's in science and library science/ technology, as well as a Master's degree in educational leadership, and has earned an additional 45 credit hours beyond the Master's. She is certified as a principal as well as a superintendent. Previously she served as a high school science teacher for 10 years, a library media/technology teacher for three years, and an assistant high school principal for four years. 


\section{Triad 2}

Teacher 2. Teacher 2 currently serves as a special education English and social studies teacher for grades seven through 12. She serves students with LD, BD, autism, and mental impairments (MI). She delivers services via co-teaching, pull out, and two self-contained classes. This is her first year in this position. She is certified to teach elementary education, special education K-12, and Autism K-12. She has her bachelor's degree in elementary education and special education and is currently working on a reading specialist master's degree.

Mentor 2. Mentor 2 is a physical education teacher. She has been in this position for 22 years. Prior to that position she served as a special educator for eight years. She is certified to teach health, physical education, and special education. Mentor 2 has earned a master's degree with an additional 30 hours. This is her first time as a Mentor; along with Teacher 2 she is also mentoring a general education teacher.

Administrator 2. Administrator 2 is an assistant principal at a building that houses seventh through twelfth grade. He holds a bachelor's degree in education and a master's degree in education leadership. He is certified to teach general science in fifth through twelfth grade, be a supervisor of instruction in kindergarten through twelfth grade, and be a superintendent. This is his first year in this position. Prior to serving in his current position, he taught general science at a high school for three years. He received mentoring last year in his first year as an administrator. His mentoring was similar to that of a beginning teacher. He had scheduled meetings with a veteran administrator and county level induction supports. 


\section{Setting}

The setting for this study was a rural, county school district in West Virginia with low attrition. The county consists of two high schools, two middle schools, and eight elementary schools. There are 4734 students in the district and $98 \%$ are Caucasian. Half of the students in the district are of low socio-economic status. The average class size in the county is 18.6 students. The county has an $88.72 \%$ graduation rate.

Evaluated by WESTEST-2 results, five schools made adequate yearly progress (AYP). One high school, a middle school, and one elementary school failed to reach AYP for the first year. An elementary school is in its second year of failed AYP and a middle school failed to reach it for the third year.

\section{Instrumentation}

After participants were selected, an email (see Appendix B) outlining the participant's role, time commitment, and compensation was sent to each participant. Further, this email requested times and dates the participants were available to be interviewed and observed. Each participant responded with dates and times they were available. A date and time was selected for each participant, and an email was sent to confirm the time. Also, in the confirmation email a short demographic questionnaire (see Appendix C) was attached. The questionnaire was consistent across all participants; however, certain questions only pertained to the beginning special educators.

Semi-structured interviews were utilized for this study. Semi-structured interviews allowed data to be gathered based on the subjective viewpoints of each participant (Flick, 2009). The subjective viewpoints provided the perceptions of each stakeholder and were used to construct an overall description of the induction program. 
In order to provide the interviewee with an opportunity to expand on their perceptions of the topic, the questions were open ended.

\section{Data Collection}

Upon IRB approval the following steps were taken:

1. Contact was made with the county to request possible participant names and email addresses.

2. Recruitment emails were sent to potential participants.

3. Selected participants.

4. Sent participant letters and demographic questionnaires.

5. Received informed consent for all participants prior to interviews.

6. Interviewed beginning special educators.

7. Interviewed Mentors.

8. Observation of Triad 2 removed due to participant request.

8. Interviewed administrators.

9. Observed and recorded mentoring session.

Interview questions for each of the three groups of stakeholders shared similar themes (e.g. challenges of beginning special educators, role of Mentor, and special educator retention), but differed in some areas due to the stakeholder's role in the induction process. Each interview was conducted individually. The interviews were conducted at the participant's school and were completed within 35 minutes. The observation occurred at a local restaurant, which is the customary mentoring session for Triad 1 and lasted approximately 40 minutes. 
Interview Protocol. The participants were asked questions (see Appendices A, $\mathrm{B}, \& \mathrm{C})$ that allowed each to provide their thoughts and opinions about the characteristics of their induction program. Further, questions were designed to provide each with an opportunity to provide their perceptions of the characteristics of an effective induction program. The interviews were scheduled outside of school hours to avoid taking valuable time from the special educator and Mentor. Each of the administrators was interviewed during school hours at their request and convenience. Allowing the participant to expand on their answers and provide as much information as possible was paramount to this study.

Upon arrival, I met with the special education coordinator or building principal to find the room for the interviews. Prior to explaining the study and gaining informed consent I talked with the participants to develop rapport and make them feel more comfortable about the interview. I assured them any answer was correct since I was looking for their perceptions. Before each interview began I explained the study and the participant's rights and responsibilities before each signed the informed consent. I reminded each participant that I would be audio recording the interview session in order to be active in the interview process and have an accurate account of his or her responses. All questions were asked in a sequential, consistent order. Participants were permitted to expand on each question without interruption. When a participant digressed, he or she was reassured and prompted back to the original question, if needed. Once it was apparent they were done providing information on the topic, the next question was asked. The questions were asked from most broad to most specific. This design allowed the participant to provide answers without being led. 
The interviews for each of the three groups (i.e., beginning special educators, Mentors, and administrators) were administered in the same fashion. However, due to the differences in their positions, the questions varied. Given that the time of day and location was selected by the participants, each were held at the participant's convenience.

Observation Protocol. Mentoring is an essential component of the induction process, and observing the session provided additional data not captured during the interviews. Further, observation of the mentoring session was used to either refute or affirm the information provided during the interviews. I utilized direct observations as a non-participant. The mentoring session took place at a restaurant, as was standard practice for Triad 1. I attempted to be as unobtrusive as possible, allowing the mentoring session to take place as if I was not present. The session was audio recorded, but given that the observation was in a public setting, the session was not video recorded. The actions, words, and tone of the session were compared to the themes from the interviews to determine if there is a discrepancy or continuity between what is said, and what is done. During the mentoring session, notes were taken on the arrangement of the session, as well as the content of the conversations. The session began with Mentor 1 providing specific advice for an issue they had previously discussed. After that, Mentor 1 had a list of talking points, which she used to guide the rest of the mentoring session. The majority of the session focused on IEP development and teaching strategies.

\section{Interviews}

After IRB approval was granted and participants were selected, the interviews began. Dates and times were arranged through email. The first two interviews were Teacher 1 and Teacher 2. 
Teacher 1 was interviewed outside of school hours at the district office. There was a new teacher meeting and she was granted permission to leave the meeting long enough for the interview. The interview was held in a conference room on the second floor. The participant and I sat across from each other at a small, round table. I began the process by explaining the study and the participant's rights. Afterwards, Teacher 1 signed the informed consent. I began recording the session and asked the first question. The setting was quiet throughout the interview; the door was closed and there were no interruptions. The interview script was followed except for three occurrences when I asked her to describe part of her previous answer in greater detail. For example, when asked, "How are Mentors assigned in this district?" she replied:

I believe they try to get you someone who is at your school so it's more convenient to try and set up meeting times. But, in this case since she was the last person in this position I believe that's how we got paired up with one another. If I'm thinking correctly there wasn't another Mentor at my school at the time. Because Teacher 1 introduced a theme that was not otherwise covered in the interview, I added a follow up question, "Do you find it difficult that your Mentor is not in your school?"

The interview lasted approximately 30 minutes in length. Teacher 1 answered all of the questions in depth, and appeared calm and comfortable throughout the interview. At the completion of the interview, I thanked her for her time and informed her I would be in contact to arrange the observation of the mentoring session. As she was leaving, I asked if she would let Teacher 2 know that I was ready for the interview whenever she was available to leave the meeting. 
After Teacher 1 left she returned to the new teacher meeting and sent Teacher 2 up to be interviewed. I followed the same protocol as the previous interview. The participant and I sat across from each other. I began the interview by explaining the study and her rights as a participant. She also signed the informed consent. I talked with her for a few minutes to develop rapport and help her relax because she appeared nervous about the interview. I began recording the session and asked the first question. The setting was quiet throughout the interview. The door was closed and there were no interruptions.

There were several occurrences where questions were added based on the answers provided by Teacher 2 . She appeared flustered when providing answers about the stressors she encountered during her first year. This interview lasted approximately 25 minutes. After she finished, I reassured her that her answers were very helpful. I described how I would observe her mentoring session, although that never happened due to the request of Mentor 2 .

After both teacher interviews were complete I received confirmation on dates and times to interview Administrator 2 and Mentor 2. These two interviews were held on a Wednesday morning during school hours. However, class was not in session. Teacher meetings were being held and each of the participants was able to leave the meeting to be interviewed.

Administrator 2 was interviewed first. The interview was conducted in his office, which he shares with the principal. I followed the same protocol as the previous interview. I followed him into his office and sat at the chair across from his desk, where he then sat. I began the interview by explaining the study and his rights as a participant. 
Administrator 2 signed the informed consent. There were two slight interruptions during the interview. The principal came in to ask about a piece of equipment he could not find. Also, there was a phone call from the secretary. Each interruption was minor in nature and did not detract from the data gathered.

The interview protocol was followed; however, there were three occurrences when I asked him an additional question in order to seek further information. This was done to allow him to expand upon his previous answer to further clarify his point. The interview lasted approximately 25 minutes. At the completion of the interview I turned off the recording device and thanked him for his time.

Administrator asked if I was ready for my interview with Mentor 2. We had already established that the interview would occur in his office, so I waited for her arrival. I followed the same protocol as the previous interview. The participant and I sat across from each other in chairs located in front of the principal's desk. I began the process by explaining her rights as a participant. Mentor 2 signed the informed consent.

Mentor 2 appeared nervous as soon as she arrived for the interview. Her speech was shaky and she displayed a nervous twitch. After the interview began and I reassured her she was doing well and she began to appear more comfortable with the interview. The only time I strayed from the script for this interview was to repeat one question at her request and to reassure her that the answers she provided were helpful.

Due to her nervousness, the interview was brief and lasted approximately 15 minutes. After the interview we discussed the Mentor's career as a special educator and now physical education teacher and the changes she has witnessed in service delivery methods. She appeared calm and comfortable after the interview had ended. Before 
leaving, I scheduled a time to observe her mentoring session the following Wednesday at the same time. I thanked her for her time and her honest responses.

Two days after I interviewed Administrator 2 and Mentor 2 I received an email from Administrator 2. He explained that Mentor 2 no longer felt comfortable having her mentoring session observed. I emailed Mentor 2 to explain other options, but she still declined to have her mentoring session observed. However, she did give me permission to use the interview for my study.

The following day I observed the mentoring session between Mentor 1 and Teacher 1. This was my first encounter with Mentor 1 so I explained the study and her right as a participant. Mentor 1 signed the informed consent.

The session took place at a restaurant, as was typical practice for Mentor 1 and Teacher 1 . The restaurant was crowded but not noisy or distracting. Mentor 1 and Teacher 1 were seated at a booth in the back, which provided privacy. I audio recorded the session. I was a non-participating observer. In order to record the session and take notes I had to sit at the same booth as the participants. I explained prior to the session that I would sit not interrupt them at any point. I instructed them to conduct the meeting as if I were not there.

The mentoring session progressed naturally and with little interruption. Mentor 1 explained that they began meeting for dinner as their mentoring sessions because of the after school work they both do. The session lasted approximately 40 minutes. The two participants discussed issues Teacher 1 was having. Mentor 1 also had a list of talking points, and they covered each one. After the list was completed they talked about other 
things such as books and movies. Before we left I scheduled a date and time to interview Mentor 1.

Eight days after I observed Mentor 1 and Teacher 1 I interviewed Administrator 1 and Mentor 1 at their school. The interview with Administrator 1 was conducted in her office during school hours. She left the door open to her office. She sat at her desk and I sat at a chair across from her. There were two minor interruptions. A teacher knocked on her door and brought her papers that they discussed briefly. The second interruption was a phone call from the superintendent, she instructed her secretary to tell him she was in a meeting and would call him back. Neither of the interruptions detracted from the interview.

The interview script was followed aside from two instances where clarification was needed. The participant was comfortable throughout the interview. The interview lasted approximately 25 minutes.

By the time I completed my interview with Administrator 1 the school day had ended, and Mentor 1 was available to be interviewed. I had already received informed consent from Mentor 1 prior to observing the mentoring session and therefore just reminded her of the purpose of our interview. She had requested that we meet in her classroom, so we sat at a round table across from each other. The classroom was quiet except for one interruption when another teacher came in to get something for the after school program.

Mentor 1 was very relaxed throughout the interview. The interview script was followed aside from three instances, two of the additional questions dealt with the idea of trust as the basis of a mentoring relationship. Mentor 1 mentioned trust as the basis of a 
mentoring relationship, then I asked, "How do you think that trust is built in a Mentor mentee relationship?" and "Do you feel a Mentor mentee Mentor relationship can work without that trust you talked about?" The interview lasted approximately 30 minutes.

\section{Data Analysis}

Interviews. I transcribed the recordings upon completion of the interviews. I used Express Scribe, which is a software program that allowed me to slow down the recording. Conventional content analysis was used to analyze the interview transcriptions. Conventional content analysis was chosen because of its intended use to describe a specific phenomenon (Hsieh \& Shannon, 2005). In this case the stakeholders' perceptions of the induction process the phenomenon. After the interviews were transcribed, I played the audio recording and read along to ensure accuracy of the transcriptions. When needed, I made edits to the transcriptions to reflect exact wording and expressions.

Once the transcriptions matched the audio recordings, I read the transcript in its entirety and immersed myself in the data in order to gain an understanding of the data as a whole. During the second reading I highlighted specific words that I believed represented significant thoughts or perceptions. Names were given to each phenomenon, in order to determine reoccurring themes. I took notes on the words and phrases highlighted in the transcription. I examined the highlighted words and phrases in order to arrange the concepts into clusters of codes. The text was read again, searching for occurrences of the codes. The codes were then categorized into specific themes, which were apparent in the transcripts. 
Observations. The observation notes and videos were examined to find themes similar to the ones from the transcriptions. They were reviewed to find any potential new themes. Deductive analysis was used to analyze and compare the data gathered from the observations to the data from the interviews. Deductive category application is the process of determining the similarities and differences between two sets of data.

The themes from the interviews were compared to the themes from the observation to examine any similarities and discrepancies. The themes were then examined to determine their relationship to the research questions.

Themes and codes. Upon analyzing the interviews and observation data codes were identified. These codes were organized into broad themes. The themes that emerged were induction as a multilayered system of support and challenges to the induction process.

The theme that induction is a multilayered supports system emerged because of several codes that were combined. District level support was a code that all six participants discussed. The participants all mentioned the special education coordinator as the main source of support for beginning special educators. The site level support is another code that emerged. The participants discussed the support they received at the site level from the principal, their mentor, and the PLC meetings. Teacher preparation programs were discussed as a source of support. The perceived support was the readiness of the beginning teacher for their first year. These codes were combined to form the theme of induction as a multilayered support.

The second major theme that emerged from the identified codes is the challenges to the induction process. The lack of realistic expectations by first year special educators 
was one code that contributed to this theme. Also, participants discussed a lack of knowledge about the special education process. Another code that leads to this theme is classroom management issues. The participants discussed the need for help with the paperwork, behavioral issues, as well as schedule development.

In the following chapter these codes and themes will be represented according to the research questions they helped answer. Pertinent quotes will be provided to display the thought process behind the codes and themes that emerged. The data will be analyzed and findings will be presented to answer the research questions. 


\section{CHAPTER 4}

\section{Data Analysis and Findings}

This study was designed to investigate the stakeholders' perceptions of the challenges and provided supports for beginning special educators. The sections of this chapter are organized around the four research questions (1) What are stakeholders' perceptions on the efficacy of their induction program? (2) What are stakeholders' perceptions of characteristics of an effective induction program? (3) What are stakeholders' perceptions of how teacher preparation programs prepare special educators for the challenges of being a beginning teacher? (4) What are stakeholder's perceptions of the challenges beginning special educators encounter?

\section{Question 1: Efficacy of Their Induction Program}

This section will describe the themes associated with Research Question1: What are stakeholders' perceptions of the efficacy of their induction program? Each of the stakeholders' provided their perceptions of their induction program. There was consensus among each stakeholder that the induction program and supports were beneficial to him or her as beginning teachers. However, there was disagreement when asked about their perceptions of an induction program's influence on special educator retention.

All participants indicated that varying levels and types of support aided in their successful indoctrination into the teaching profession. Support took many forms throughout the interviews, and although there was differing emphasis across roles of the participants, all agreed that perceived support encouraged, buffered, and strengthened their first year experience. The overarching themes were mentoring, administrative 
support, and development of a Support System. Codes emerged within each of the themes (i.e., district and site level supports, and PLC meetings).

Administrative support. Administrator support is essential in order to have an effective induction program. District and site level administrators have the ability to provide the time and support needed to promote effective induction. Administrative support at the district and site level emerged as a theme. In the following discussion, the distinction of perceived support at both the district and site level will be presented.

District. A unifying theme across all interviews and the observation the special education coordinator as the main source of support for beginning special educators. All six participants mentioned the special education coordinator as the main source of support. When asked what the main supports provided for beginning teachers, Teacher 2 simply answered with the special education coordinator. Prompted to expand her response Teacher 2 continued that as soon as she encountered a problem her first call was to the special education coordinator.

Oh, like if there's a process I don't know because um I am in my first year in the high school special ed like uh, she talked me through the IEP like when I'm doing a meeting and that kind of stuff... Like, um, there's a manifestation that we had to do so she helped me out with that, so... Um, (special education coordinator) is very helpful. All I have to do is shoot any email to her and she'll respond right away.

Additionally, both Teacher 1 and Teacher 2 named the special education coordinator as someone who provided them with extensive support. Teacher 1 explained how ideal her relationship is with her Mentor, yet still mentioned seeking help from the special 
education coordinator. Teacher 2 felt her Mentor did not provide her with a lot of support due to the fact that she did not teach in the field of special education.

Every Wednesday she comes in and has me sign papers. I see her every once in a while and she asks how I'm doing. She's I mean she's there for me support-wise. Making sure I'm not too stressed and everything. But, uh, but not having someone that I can actually go to and show me how to do this is frustrating.

Subsequently, Teacher 2 named the special education coordinator as her main source of support.

The support of the special education coordinator went beyond simply providing direction or guidance. For example, Mentor 1 is not in the same building as her mentee. In order to facilitate a positive mentoring experience the special education coordinator provided Mentor 1 with a substitute for five half days. During these five days Mentor 1 was able to observe and provide advice based on these observations that was only possible due to flexibility and supports to spend those valuable teaching days together provided by the special education coordinator. When asked about how Mentor 1 is able to properly Mentor the beginning special educator, he said:

...(special education coordinator) gave me at the beginning of the year I had, five or six half days to go spend with her. We spent some time over the summer you know, it's just now that we gotten to the point where we meet for dinner after school. So I would go see her at the beginning of the year... Mentor 2 she kind of took care of making sure they had everything they needed if there was something they needed to know specifically about special ed, she took care of it. 
The supports provided by the special education coordinator range from direct contact with the beginning special educators to providing time for the Mentors and principals which afford them the opportunity to provide help for the new teachers. Administrator 1 stated the special education coordinator is the type of person that the beginning special educators can go to when they need help on a variety of topics. She cited the quick responses by email and the fact that all special educators can contact her via text message as two reasons why she is so accessible.

Administrator 2 credited the special education coordinator as his source for all the special education knowledge he required.

I mean, it's just nice, I think the strong support is just someone you can go to that has an answer, and how quick you can get that answer. That's what's good about (Special education coordinator)... (Special education coordinator's) the guru.

That's who we go to, we go to (special education coordinator).

Through transcript review, the fact the Special Education Coordinator was accessible and knowledgeable was viewed as a key component of the induction process. Beyond the district level, the participants discussed the need for guidance and support at the site level. Participants highlighted the various supports providing by the Principal.

Site. The need for a strong and supportive leader in the principal role was noted across participants. Although the types of support varied, each participant described the impact of the relationship with an effective principal holds for a beginning teacher. Teacher 1 described how her principal provided her with support.

That's a big thing. I've been lucky at both schools that I'm at the principals have been helpful and supportive. I know if I need something I can go and ask and 
they'll help me the best they can. If they don't know exactly how to answer it they're able to direct me to someone who could.

Teacher 2 gave specific supports her principal provided.

Um, our other principal. He does a really good job like if we have any concerns with behavior. He's always trying to help out with that...

Administrator 1 believes beginning special educators need a principal to help them become acclimated to their new school.

I think they need a good principal. Honestly I think they need to be able to come to the principal right off the bat.

Administrator 2 explained the specific supports provided by himself and the other principal in his building.

...now that we do these PLC's, which is another support for beginning teachers because once a week we have an hour and like right now I imagine Mr.

(Principal) is up there and he'll split, what we're different here is we have a middle school.

Additionally, the principals conduct Professional Learning Committee (PLC) meetings. PLC meetings are designed to address any problems beginning teachers may have. Every Wednesday morning the faculty meets as a grade level, then as a department. The principal or assistant principal lead the meetings. Each meeting has an agenda and may cover any problems or situations the principals want to address. For instance, the meetings may cover the state testing and the protocol the school will follow when administering the test. These meetings also provide beginning teachers with an opportunity to ask questions about any issues they may encounter. Administrator 2 feels 
providing the beginning teachers with this formal time allows them to connect with more experienced teachers "During the PLC time, just to have other teachers it just gives them an hour where you can sit down with somebody who already knows the program."

Support system. Support at the site level varied from interpersonal aspects such as learning the climate of the school, to a more structured routine with meetings and observations. These supports are both formal and informal in nature and give the beginning special educator the opportunity to seek advice for specific challenges. From this, the codes of structured meetings (PLC Meeting) and relationships were noted.

PLC meetings. Each participant in Triad 2 found that participation in PLC meetings was positive and provide support for their teaching and beginning experiences, while no participants in Triad 1 mentioned these meetings as a source of support. Teacher 2 discussed how her Mentor used the PLC meetings as their mentoring session. No, like PLC's she'll sometimes ask then but I don't think that's set aside for mentoring sessions. I don't believe. Um, that's supposed to be for the students getting things ready for that. She'll ask and everything and take note of stuff that I'm concerned with.

Mentor 2 concurred with her mentee, "We generally meet during their PLC, and that's kind of when I catch up with where they're at." This comment suggests Mentor 2 views the PLC meeting as their mentoring meetings, while Teacher 2 does not feel PLC is when mentoring should take place, 'I don't believe. Um, that's supposed to be for the students getting things ready for that." Mentor 2 utilizes PLC meetings to check in with her mentee rather than having specific one on one mentoring sessions once a month, "Other 
than meeting, we've never really had just a mentoring meeting." Administrator 2 described his thoughts on the importance of meetings as an induction support.

PLC is what's nice. They have this time allotted when they can meet. I mean we have designated stuff they can talk about each week. They sit down and talk about (General Education Teacher)'s kids, and all the different benchmarks. We give them a list. Then they get some time where they just get some more meeting time, that's what's so great they just get time to meet with all the other teachers. I think that's where I learned more than anywhere. I think PLC's the best for new teachers, I really strongly feel PLC's is more important than anything.

Relationships. A positive relationship between the Mentor and mentee is an essential component of effective mentoring. This relationship must be built on trust in order for the mentee to feel comfortable asking for advice. The induction supports in this county came from a variety of sources. Along with the administration and the assigned Mentor, other colleagues also provide support for beginning special educators.

Teacher 1 relies on other teachers in her school when she has a problem with a specific student. She is able to talk with teachers that student has in order to rectify the issue.

Other teachers, they are all very helpful if I'm having an issue with a specific grade level I can go to any of those grade level teachers and kind of ask for advice or do you have any resources that you may not be able to use in your classroom that you feel might benefit these students. I've not ran across anyone that was not willing to help, so I've been very lucky with that.

Teacher 2 benefits from a colleague who previously taught in special education. 
Uh, there's another teacher who worked in special ed for a long time and now he just teaches social studies and history. He's always there and he even gave me a book on behavior, like what to do. If I have questions he's pretty good about helping me out with that... Like if I have questions about specific students she's pretty good about saying she'll work with them if they're being a behavior problem and that kind of thing.

The main themes found in the data that assisted with answering Research Question 1 are Mentoring, Administrative Support, and development of a Support System. Each participant reflected on their induction process and provided valuable insight into the current induction.

\section{Question 2: Characteristics of an Effective Induction Program}

This section will describe the themes associated with Research Question 2: What are stakeholders' perceptions of characteristics of an effective induction program? Four of the six participants cited an effective Mentor as the main characteristic of an effective induction program. The overall theme was the need for varied types of support to guide the beginning teacher through challenges faced in their first year. Stakeholders' perceptions of an effective mentoring program consisted of a Mentor, administrative support, and the overall support system in the county.

Characteristics of effective mentoring. Although there were mixed opinions on the types of support needed each participant cited an effective Mentor as an essential characteristic of an induction program. The relationship and mentoring are perceived as a critical piece of an effective induction program. According to the views of the participants, Mentors present a knowledgeable, experienced, confidant who can guide the 
beginning teacher through the special education process in their first year. Participant perceptions suggested the Mentor should posses certain personal qualities such as good communication skills; also they must be available to provide quick answers to questions from beginning special educator.

Due to the overwhelming amount of paperwork special educators must complete support is needed to ensure the paperwork is completed properly and in a timely manner. Availability and ease of communication are two factors that may help or harm a mentoring relationship.

Special education process. The special education process can be difficult to negotiate for beginning special educators. Support from Mentors can help make this process more efficient. Teacher 2 expanded on her opinion that Mentors are the most important induction support for beginning teachers.

Yes, I think that support-wise it would be good for trainings on like the whole process of IEPs, the whole paperwork. I keep bringing up paperwork, but that's all special ed is. Um, like having uh training on that kind of stuff would be very helpful for first year teachers

Later in the interview Teacher 2 reiterated her opinion of what supports a Mentor should provide.

Someone who knows what they're doing. Um, who knows the process, and um who's there for questioning. Um, I think to bounce ideas back and forth. Um, I don’t know.

Mentor 2 concurred with the opinion that Mentors should provide guidance for the beginning special educator on the special education process. 
Because they just stepped into a brand new world. So they need someone to say ok, IEP's are due then, these are triannuals, this is testing, this is benchmark. Someone who's been through the system who can put those things in order so they don't feel so bombarded.

Administrator 1 stated, "If they're nervous about being a first year teacher and not knowing what to do somebody actually takes them under their wing. Somebody shows them the guidelines..."

This theme was supported by the observation of a Mentoring session between Teacher 1 and Mentor 1. During the 40-minute mentoring session the majority of the discussions were focused on the special education process, with IEPs making up most of the conversation. More than knowing the process, each beginning teacher described personal characteristics that facilitated a relationship where they felt comfortable reaching out to their Mentor. Although, there were different opinions about the specific qualities, each described how the connection to their Mentor supported them beyond the paperwork.

Personal qualities. The personal qualities of the Mentors emerged as a code. The participants believed Mentors must possess certain qualities that allow them to provide effective support. These qualities help them provide the mentees with timely and personal advice.

Mentor 1 summed up this theme when asked about mentoring, "More than knowing the process, each beginning teacher described personal characteristics that facilitated a relationship where they felt comfortable reaching out to their Mentor. Although, there were different opinions about the specific qualities, each described how 
the connection to their Mentor supported them beyond the paperwork. Teacher 1 listed the characteristics she believes a Mentor should posses.

I think they need to be someone who's flexible, organized, reliable, patient. That's a big one. They just need to be there for the right reasons. They need to be there to want to help you otherwise that could be very overwhelming for them and I guess us or the person they are mentoring... They need to be good at communicating. Teacher 2 added, "Knowledgeable... The skills they are mentoring in." Administrator 2 had a similar opinion about the characteristics that are most important.

Basically someone who knows what's going on... As far as characteristics, someone in the know... I like them organized. Communication skills, be able to tell them what they need to have. They have to be motivated. I'd like them to be professional.

According to the participants the characteristics most needed by an effective Mentor are flexibility, good communication skills, and knowledge of the special education process.

Experience. The participants cited special education teaching as an important trait for a Mentor to have. The participants believe experience allows the Mentor to provide advice and suggestions backed by their own experiences.

Teacher 1 benefits from having a Mentor who held her current position the prior school year. She believes this has helped her Mentor guide her through the challenges she has encountered.

Someone who may have faced the same issues. May have been in the same position or just have the experience... I think right now years of experience kind of exceeds anything, cause I think I feel the longer you do something the more 
you get to see. So the more options, I guess it's more likely for them to come across that you may be experiencing.

Although Teacher 2 had a different experience, her answers supported the need for a Mentor with relevant experience.

Um, like I understand that she had a special ed degree at one time, my Mentor, but I think she taught it one year then did PE the rest of the time. She has the degree, but not the experience as well. I think they need to have the experience as well as the knowledge

Teacher 2 further explains her frustration with having a Mentor that lacks that shared experience

But like I said she didn't have, I mean she had information, but it wasn't what we needed... And, can't really go to her for questions... She can't really help me if she doesn't know herself.

Administrator 2 described the need for a Mentor with relevant experience.

I mean hopefully, show them hey you need to get this done. Lesson plans need to be this way, what they need to do, what they need to have in. Mentor's also, as far as telling them about paperwork and all the logistics. They need to tell them, as do the administrators, how things work around here.

Mentor 1 believed that experience is a necessity in order to Mentor a beginning teacher, "Yeah, if that is where it comes from then yeah. Because if I don't have that experience how am I going to guide her? I guess that's the bottom line." Administrator 1 believed experience within the building is paramount in an effective Mentor. 
Someone that has enough experience has enough time in to kind of know this system. As you know education is its own system, its own business. I think it's better to have somebody here for that person.

Mentor 2 discussed how a Mentor can provide specific information to beginning special educators.

There's behavior issues you have to deal with and sometimes they might ask me a question about a specific student you know. You've been around that student for $\mathrm{x}$ amount of years, you know them better tell me a little about them. I'm more of a liaison to them.

Administrator 2 echoed the need for the beginning teacher to have a Mentor with experience, yet suggested that some supports may not need to be discipline specific. I mean when you're first hired you are overwhelmed; a lot of teachers are overwhelmed. Um, and you know just helps them feel comfortable and someone shows them, for the most part, not too many teachers, unless they sub for several years are going to know how to take attendance, know how to put grades in grade quick, and know all the jargon now that we are throwing out.

The observation confirmed the opinions of the participants. Throughout the mentoring session Mentor 1 referred to situations she experienced when providing Teacher 1 with advice and possible solutions to problems she was experiencing.

Availability. Teacher 1 and Teacher 2 had different experiences with the availability of their Mentor, but each confirmed the importance of the accessibility. The location of the Mentor is a code that emerged with differing opinions. Teacher 1 and Mentor 1 are not located in the same building and neither of them believes the separate 
location presents a negative effect on the efficacy of the mentoring due to the fact they developed alternative ways to keep in touch. However, Administrator 1 strongly believes the Mentor should be in the same building, even at the expense of experience in the field of the beginning teacher.

Teacher 1

No, I could see that for maybe other cases being an issue but for us it's not. Just because she's been so open and I have her cell phone number I have a million ways I can contact her and she's always been ok with that. No matter what time, whenever, I can contact her very easily.

Mentor 1 had held a similar opinion.

No she is not [in the same school], she does an after school thing here, but that's it. But (Special Education Coordinator) gave me at the beginning of the year I had, five or six half days to go spend with her. We spent some time over the summer you know, it's just now that we gotten to the point where we meet for dinner after school. So I would go see her at the beginning of the year.

Conversely, Administrator 1 believes being in the same building is more important than experience in the same field as the mentee.

I think their Mentor teacher needs to be in the building. I'm kind of big on that. I have a new teacher here and I got to pick her Mentor between someone in our building in a different field and someone out of the building in the same field. I picked the person in the building. Just because they know what's going on, they can help them out while they're here... I think each school has a different culture. When I made that decision I knew that my uh teacher that was mentoring my new 
teacher would be here and she could stop in she could meet on the fly, she could see her at lunch. It didn't have to be scheduled, you know. I just strongly feel that person, whether it's in the field or not in the field. I think it's better to have somebody here for that person.

While Administrator 1 believes learning the culture of the building is the most important job of a Mentor, Teacher 1, Teacher 2, and Mentor 1 disagree. Although Teacher 2 is in the same building as her Mentor, Mentor 2 has not taught in special education for over twenty years. Teacher 2 stresses the importance of experience within the field, rather than location, as the most important quality of a Mentor.

Every Wednesday she comes in and has me sign papers. I see her every once in a while and she asks how I'm doing. She's I mean she's there for me support-wise. Making sure I'm not too stressed and everything. But, uh, but not having someone that I can actually go to and show me how to do this is frustrating. Administrator 2 describes some of the orientation supports.

They bring them in, the first thing is getting all their paperwork done as far as getting their employee ID, their web ID... They sit down, they just start from square one and tell them about the code of conduct and they go through sexual harassment videos and other things like that

When asked what the most important supports for beginning teachers are, Teacher 2 responded, "Someone who knows what they're doing. Um, who knows the process, and um who's there for questioning. Um, I think to bounce ideas back and forth. Um, I don't know." 
Effect of mentoring. The participants provided mixed opinions on an induction program's affect on teacher retention. When specifically asked about the induction program's impact on special educator retention only one of the participants answered that it did. Administrator 2 answered, "Without a doubt." The theme that emerged was that induction provided support for the beginning teachers but did not influence retention. Both teachers provided similar answers. Teacher 1:

Um, I love what I do. I don't think I would ever want to go to general ed and I think it's just more because all my observations and field training has been in special ed. Even though the paperwork is a lot and it's not all that fun, it's still worth it. But I wouldn't say these meetings have influenced that either way.

Teacher 2 responded:

I enjoyed working in special ed, I'm not going to leave it. Um, but I like working with students in special ed still. If there was something of that sort to come up, or um anything I don't know. Uh, just better, sometimes the working environment isn't great, but that's every work environment. I don't know if that would change it or not.

Administrator 1 and Mentor 1 had similar perceptions on the induction program's impact on retention. They both believe the induction program does not influence retention, not because it is lacking, but rather because there is more intrinsic qualities that retain teachers in the field of special education. Administrator 1 said:

Well, there are two types of people... you're cut out to be a special educator or you're not. It takes a special person... You really have to be a special person and I don't think you learn that. I don't think four years of college makes you a special 
educator. I really think it comes from inside, if you're going to stay. I don't think any program is going to promote you to stay in special education if you are just not that person.

Mentor 1 provided a similar answer:

I think it depends on the person. Now seven years later we've the county has hired a lot of special ed teachers who are not going anywhere. I don't know that the Mentor relationship or the induction program had anything to do with that. I think it's the personal qualities. These people have wanted to be special ed teachers all their lives. We joke, I'll die a special ed teacher, (Teacher 1) will die a special ed teacher. I don't know that the induction program has any, I think the induction program has more to do with how effectively they do their job or how much they know about paperwork and that kind of stuff.

The stakeholders' perceptions provided data that produced the theme that varied supports are needed for an effective induction program. The codes that support this theme are the need for an effective Mentor who possesses knowledge of the special education process, certain personality traits, experience, and availability. Also, a code emerged that the induction program does not have an effect on attrition and retention according to the stakeholders' opinions.

\section{Question 3: Teacher Preparation Programs}

This section will describe the themes associated with Research Question 3: What are stakeholders' perceptions of how teacher preparation programs prepare special educators for the challenges of being a beginning teacher? Both beginning teachers 
provided their perceptions of their preparation program and how the program prepared them for their first year as a special educator.

Field experiences. Teachers 1 and Teacher 2 had different perceptions on how their preparation program prepared each for their first year as a special educator. Although their experiences differed they showed the common theme of the need for more practical instruction.

Teacher 1 and Teacher 2 had opposite opinions on their field experience. The stakeholders' perceptions showed the need for varied placements, longer practicum, and providing pre-service special educators with a realistic idea of their first year.

The main difference between the field experiences between the beginning teachers was Teacher 1 did not believe her field experience helped, while Teacher 2 credited her field experience as the most important aspect of her preparation program. Teacher 1 is a gifted teacher and none of her placements were in a gifted classroom. I was actually on the other end of special education for all my observations. Gifted is not where I ever really saw myself. So I can't say any of my observations have helped with that.

Teacher 1 credited two online classes for preparing her for her current position. I did take two online gifted and talented courses and I think it helped me realize these kids still do face problems. I mean not everything comes easy for them. There's things you may think that they automatically get and I find myself realizing, ok no you do have to take a step back. They still are kids and they don't always fit that stereotype that they just get it. They still have to work at some things to. 
She discounted her field experience since none of it was in gifted placements.

Teacher 2 had a completely different perception.

I think field experience helped me more than anything. Especially when I was student teaching, I did four different placements. I think those helped out a lot.

Administrator 1 described the negative aspect of a singular field placement.

So I think if you get a snapshot of a classroom before you actually get your own classroom and it's good and the teacher has good control when you begin you don't know about classroom management, I mean you've heard of it, somebody told you about it, but actually doing it is a different thing.

Realistic expectations. Another theme that emerged was a beginning special educator's lack of realistic expectations for their first year. Although students are exposed to a variety of coursework and field experiences, all participants suggested that those experiences alone do not adequately prepare beginning teachers to having a classroom of their own. Administrator 1 discussed the need to better prepare special educators for their first year.

I don't think they always know what they're getting into... So I think, I don't think, I don't always think that college offers the whole real world scenario. I know they're doing better letting students get into the classroom more and observe more, and longer student teaching time. You really need to infuse yourself into that situation if you're going to be a special ed teacher.

Teacher 2 discussed her expectations of her first year, and what was asked of her. 
Um, I knew there was going to be a lot expected and basically I was informed that I was going to have to kind of be the head of it, which I didn't want to because I needed someone to lean on too.

Mentor 1 provides her opinion on the need for practical lessons.

I think it has to be, because I sat through a lot of classes. You know what, give me theories all you want, it's not going to help.

Mentor 1 continued to talk about the lack of realistic expectations special educators have about their first year.

People have this vision of what a special ed teacher's going to be, then people walk in and say really? I'll tell you what, this job I'm in now I couldn't have done my first year. I got one who an turn on a dime. Can be the sweetest little thing, next thing you know she's on the floor throwing a tantrum. I'd a never been ready for that and I started when I was twenty nine, let alone a twenty-two year old kid. Mentor 2 concurred that it is difficult to have a realistic idea of s special educator's first placement.

It's a whole different world than a regular ed teacher. They are dealing with a variety of students with a variety of needs and you have to try and get to know that student. I thought they are thrust into it to be honest. They are like here, this is what you got to deal with. And trying to get to know the student plus do the testing that needs to be done, and follow this student up for resource time.

Administrator 2 agreed that beginning special educators must be told what is expected. When I get a new teacher I really need to let them know our expectations. They need to turn in lesson plans, classroom management 
Coursework. Coursework is an integral part of any teacher preparation program. There is a need for educators to have a strong foundation in pedagogy, teaching strategies, student characteristics, etc. However, the beginning teachers agreed that there were some needs that were not met through their coursework.

Teacher 1 felt there was a need for more varied topics in her coursework, "Um, I think course work was a lot of repetition, yes I know who Piaget is, but I think mainly my field experience rather than the coursework..."

The special education process emerged as a theme from the interviews. Teacher 2 felt her coursework did not properly prepare her for the IEP process, "cause I think some of the coursework should have dealt with more of the IEP and paperwork than what they did teach us."

Mentor 1 had a similar opinion on the need for better IEP preparation.

I don't know about now. I'll give you a little bit of when I went through I never had to write an IEP. When I got out and I had to write my first IEP, thank god that I had made some close contacts with teachers at (high school) because they talked me through everything.

Teacher 1 felt unprepared to complete IEP online coming out of her preparation program. I did actually, we didn't do online. We did just the regular format I guess it is. So not the online version. So I had a little idea of what to expect, but as to navigate the program in itself it can be difficult.

Administrator 2 agreed that paperwork is difficult for beginning special educators, “...to go to her because she knows all the laws and how to get the paperwork in, it's just I think that is the hardest thing for them." 
The themes that emerged to help answer Research Questions 3 are the need for varied placements during field experience and coursework that focuses more on practical knowledge. The codes that formed the varied placement theme are the need to provide a realistic portrayal of the first year as a special educator during the preparation program. The codes for the coursework theme are the need for varied coursework, and more IEP preparation.

\section{Question 4: Challenges Beginning Special Educators Encounter}

This section will describe the themes associated with Research Question 4: What are stakeholders' perceptions of the challenges beginning special educators encounter? Each of the stakeholders' provided their perceptions of the challenges beginning special educators face. The main themes were the special education process and variety of learner needs.

Special education process. Each of the participants was asked about the challenges beginning special educators face. The special education process was one of the main themes that emerged. The stakeholders believed the online IEP system, schedule development, and student familiarity are the components of the special education process that cause the most stress.

IEP process. Both beginning special educators were asked directly about the stressors they encountered as first year special educators. When asked about the main stressors she encountered Teacher 1 answered:

The paperwork and the IEPs that are online, um it's difficult to keep track of the order in which the paperwork needs to be filled out and turned out and you have 
to wait so many days before you can take the next step. I think that's been the biggest thing. Just trying to get that all straightened out and to find a system. Teacher 2 responded to the same question:

Um paperwork and uh IEP's that aren't very detailed, students you don't know. Throughout the interviews each teacher mentioned paperwork several more times. They brought up this theme when talking about supports they were provided and questions they asked the special education coordinator. While discussing the supports she received from the special education coordinator, Teacher 2 once again discussed the stressors she encountered:

...if there's a process I don't know because um I am in my first year in the high school special ed like uh, she talked me through the IEP like when I'm doing a meeting and that kind of stuff... Like all that paperwork and the meetings and the IEPS are new too, because it's all computer based now.

Teacher 1 stated, "All my IEPs, not all of them, most of them were due before I even got to meet my students. So to actually write IEPs for students I didn't know, that was difficult." The theme of paperwork as the main stressor was evident throughout the study. Three of the six participants have special education experience, and each of them mentioned the process as a main stressor.

Schedule development. The difficulties developing a schedule for the students and teachers emerged as a theme. Teacher 2 was given the responsibility of creating her own schedule at the beginning of the school year.

Uh, we have to make our own schedules to um meet all the students' needs. Like to know where we need to be during specific times. A lot of it is co-teaching. I 
only have two self-contained classes. So the majority of it we have to fit ourselves into the classes with the students that need it the most... We have to go through every single students' schedule, figure out where they're at then go from there. So, about forty some students you have to go through and figure out that, so. Later in the interview Teacher 2 discussed the stress schedule development caused her due to an audit. When asked about stressors in her first year she replied.

Uh, paperwork and getting ready for this audit... The audit they came in to see if we were we met the minutes that were required on the IEPs so we had to go through and make amendments to every single students' IEP to make sure they matched with every single minute we were with them. Like our schedule had to match their schedules and the minutes we were with them.

Teacher 1 discussed the stress that can arise from the inability to stay on schedule. There are days when you have a schedule and you know what you want to get done and there's a million things going on throughout the school and sometimes you just have to push that to the side and get done what you can and hope to make up for it the next days.

The stakeholders' perceptions displayed the importance of having a set, manageable schedule for special educators in order to manage stress.

Mentor 1 provides her opinion about special educators' schedules.

I think it's more, the biggest is time management. They're trained to be in a classroom, they're not trained to figure out how am I going to do sixteen IEPs in the Fall or in the Spring when I'm trying to teach and do all the stuff 
Mentor 2 agreed, "To help them like try to find some kind of a routine. Like I know they had to, I feel like they were just put in this job, brand new."

Variety of student needs. Students with special needs require a variety of teaching strategies. They also provide unique challenges to beginning special educators due to the variety of disabilities including learning and behavioral considerations.

Student familiarity. The stakeholders discussed a lack of familiarity with their students as a cause of stress. Upon accepting her assignment, Teacher 1 was informed that most of her IEPs were due at the beginning of the school year with limited opportunity to learn the strengths and needs of her students.

All my IEPs, not all of them, most of them were due before I even got to meet my students. So to actually write IEPs for students I didn't know, that was difficult. Mentor 1 discussed this situation and provided her perception of how it could be rectified.

Mentor 1 discussed this situation and provided her perception of how it could be rectified.

Basically because there are two schools of thought in County. Most everybody does Spring IEPs which gives you more time to prepare. I do Fall IEPs and God love (Teacher 1) she inherited all of mine.

This theme was strengthened by the observation of the mentoring session between Teacher 1 and Mentor 1. During the mentoring session Mentor 1 provided information about specific students to help Teacher 1 create teaching strategies as well as develop IEPs. 
Classroom management. Beginning teachers often struggle with designing their classroom to ensure effective learning, proper behavioral supports, and provide adequate learning materials for each student.

Teacher 1 discussed the stress she encountered trying to find materials and design lessons for each student.

I would think that would be trying to find the appropriate material. There was, like I said there's just so much out there and it's hard to pick what is best for your students. And you do want to help all the kids. They are all kid of being challenged, things like that. You just, for me I didn't know where to start. Teacher 1 continued discussing the challenges of classroom management, "But I'm finding now some of the things aren't something I think I want to continue with next year. I'd like to incorporate some new materials" Teacher 2 discusses behavioral considerations.

He does a really good job like if we have any concerns with behavior. He's always trying to help out with that but, uh like the classroom that we're in that's not really being met with. We don't have enough classrooms so everyone is in the same class

Administrator 2 discussed the difficulties special educators in his building encounter finding materials and getting help with teaching strategies due to the fact there are no other teachers teaching the same class.

There's pros and cons for being in a small school. If you are a ninth grade science teacher, or a ninth grade English teacher you're the only one here. Compared to if you're someplace like (Neighboring County), I always relate back to that cause 
that's where I taught before I got back here. I had six other general science teachers; I had six other ones there. So they're teaching the same material, as far as getting material and supplies. At a bigger school it's a lot easier

The observation strengthened this code. Teacher 1 asked about specific math learning strategies she could employ for her gifted students. Mentor 1 described materials in detail and gave suggestion on how to best utilize them.

This chapter discussed the analysis of the data collected to investigate the research questions of this study. This chapter evaluated the data collected from six interviews and one observation. A presentation of the themes and codes highlighted the perceptions of key stakeholder's in the in the induction process. A discussion of the findings as well as implications gleaned from the results and recommendations for future research are presented in Chapter Five. 


\section{CHAPTER 5}

\section{Discussion}

My purpose for conducting this study was to examine and describe the stakeholders' perceptions of their induction program, an effective induction program, challenges of beginning special educators, the efficacy of teacher preparation programs in preparing beginning special educators for their first year of teaching, and the challenges faced by beginning special educators. Also of significance was the perceived effect induction held on the retention of special educators.

The chapter will begin with a discussion of the findings based on the four research questions. Following the findings, implications will be presented with recommendations for development, implementation, and practice. Limitations of the study will be outlined prior to the discussion of future research ideas. The chapter will conclude with a summary of the findings.

\section{Findings}

The research questions that guided this study were: (1) What are stakeholders' perceptions on the efficacy of their induction program? (2) What are stakeholders' perceptions of characteristics of an effective induction program? (3) What are stakeholders' perceptions of how teacher preparation programs prepare special educators for the challenges of being a beginning teacher? (4) What are stakeholder's perceptions of the challenges beginning special educators encounter?

\section{Question 1: Efficacy of their induction program}

Consistent with the current literature, each participant perceived that a strength of their induction program was the support, both administrative and personal. However, 
their perceptions contradicted the current literature on induction program's effect on teacher retention.

The participants believed the overall support provided by their induction program helped them navigate their first year as a special educator. The source of this support ranged from the Special Education Coordinator at the district level to the principal and Mentor at the site level. The Special Education Coordinator serves as the main source of information and support for the beginning teachers. She was available to each of the participants to answer questions about the special education process.

The overall support system consists of the induction supports provided by the county down to informal supports by colleagues. Although the beginning teachers encountered many challenges in their first year, there were very few they perceived as issues that could not be helped by their support system. The participants discussed receiving support from the librarian, custodian, general education teachers, and principals.

In this study, the finding that five out of the six participants did not believe the induction program had an effect on their desire to remain in the field directly contradicts the retention literature (Wasburn-Moses, 2006). The beginning teachers believed their desire to remain in the field of special education hinged on intrinsic motivation rather than external support. They discussed the importance of their induction program but ultimately perceived the desire to stay or leave the field as something induction supports cannot change. 


\section{Question 2: Characteristics of an effective induction program}

The navigation of the various special education processes can be troublesome for beginning teachers. Therefore, a need for targeted support in this area is an essential component of induction programs. Although the beginning teachers had experience writing IEPs they still struggled to develop them in their first year. These struggles surrounded the county's use of an online system for which they had no previous experience utilizing. The supports they perceived as important were timely, informative answers to questions about the special education process. These answers most often came in the form of texts or e-mails from the Special Education Coordinator or through conversations with the principal.

Of interest, the human factor was not disregarded as playing a key role in the successful induction experience. The Teachers felt their mentor must be available to them when a problem arose. The timeliness of the received response was one of the most important characteristics of a mentor as perceived by the beginning teachers. Also, aligning with the literature, four of the six participants believed relevant field experience was needed to properly mentor a beginning special educator (Gehrke \& McCoy, 2007). Administrator 1 believed it was more important to have a mentor within the building than in the specialized area, which is in direct contrast to the literature.

All participants discussed their belief that the induction program did not promote retention among special educators. The perception that it takes a special person to remain in the field was shared by several of the participants. Their belief was that a person is either capable of staying in the field or they are not, and induction supports could not change their desire to stay or leave. 


\section{Question 3: Teacher preparation programs}

Although teacher preparation programs vary across universities, there must be consistent components included to prepare special educators for the challenges of their first year. The participants' perceptions varied on this topic. One theme shared by several of the participants was the need for practical instruction on how to negotiate the special education process. They acknowledged the presence of IEP instruction in their preparation programs, but considered the lack of support for the online software used in their county as a main stressor.

The field experience component of preparation programs was thought to be useful by some participants and of no help by others. Although the participants varied in their opinions of their individual field experiences, the overarching theme was the need for varied placement. The variety of placements would expose the pre-service teacher to different settings, different methods of service delivery, and students with differing abilities. The participants believed their field experience was helpful when it aligned with their current position. This can lead to more realistic expectations among pre-service teachers.

The participants felt many special educators enter the field with unrealistic expectations based on their limited field experience. If pre-service teachers were placed in an ideal setting, they may not expect some of the issues that arise in special education classrooms. The realistic expectations could be promoted in the preparation programs by discussing the challenges beginning special educators often encounter. This portion of 
the coursework could help prepare them for the challenges that may not be evident in their field experience.

\section{Questions 4: Challenges beginning special educators encounter}

The perceived challenges facing beginning teachers are many and varied. These challenges consist of the special education process, schedule development, and classroom management. The perceived challenges from this study align with the current literature on special educator burnout (Billingsley, 2007).

The main challenge as perceived by the participants was understanding the special education process as a whole. The participants did not feel beginning teachers were adequately prepared for the process. Beginning teachers often have experience writing IEPs in courses, but have not dealt with keeping track of re-evaluation dates, compliance factors, and parental involvement in the process. Beginning teachers often experience stress due to their inability to complete the entire IEP process without guidance, including the paperwork, in a timely manner.

The development of the beginning teacher's schedule is another source of stress. At a time when beginning special educators are still trying to determine their own role within the school environment, they are given the task to design the schedule for each of the students on their caseload. This requires them to cooperate with general educators and also figure out how to divide their time to provide the necessary services outlined in their students' IEPs.

Classroom management is a perceived cause of stress for the participants because of their lack of familiarity with the students and the materials. One participant's IEPs were due at the beginning of the school year, which left her to write many of them before 
meeting her students. Fall IEPs, preferred by the county, hinder a beginning special educator because of their lack of familiarity with the student. The beginning special educator is trying to get acclimated to their new position, learning needs of the class as a whole, and the availability of services provided in their school; therefore, the responsibility of writing IEPs at the beginning of the year causes the teacher additional stress.

\section{Implications}

Given that there is a struggle to retain quality special education teachers, it is imperative that teacher preparation programs and induction programs take into account the perceived needs of the beginning teachers to guide future research. Currently most of the literature on induction programs focuses on the ability to promote retention. However, the findings of this study suggest a closer examination of the pairing of mentors with mentees, its effect on retention, and the efficacy of preparation programs is paramount to an effective first year experience.

Teacher preparation programs must be kept abreast of the perceived effectiveness of their coursework and their field experience in order to develop a model of instruction and practice that will best serve beginning teachers. By doing so, appropriate educational experiences will provide more authentic field experience placements, exposure and meaningful interaction with special education processes (e.g., on-line IEP system, service delivery methods) and opportunities to participate in the scheduling of student schedules.

An interesting finding from this study was the strong value placed on the support from the Special Education Coordinator. Each participant mentioned the Special Education Coordinator as the main source of support for beginning special educators. 
Therefore, programs of Education Leadership need to have targeted coursework where special education law, procedures, and instructional practices are a main point of emphasis. Further, school districts must be cognizant of the reliance beginning special education teachers may have on the personnel in the coordinator position. Given that many beginning teachers may be the only teacher in their school teaching in their discipline paired with the lack of special education knowledge by school administrators, their only source of support for special education specific questions may be the Special Education Coordinator. Educational Leadership programs should contain more special education courses to familiarize future principals with the special education process. This would allow principals to provide on-site support for special educators.

Although Policy 5900 requires a new teacher mentoring program, the required components are vague and often leave the decision up to the district as to how the program is employed. Without the guidance of research-based policies, districts may fail to employ the proper induction supports. There is a need to stringently examine Policy 5900. The policy has not been updated since 1991. The research on new teacher induction and the shortage of special educators has grown and evolved significantly since 1991. The policy does not accurately reflect the needs of new special educators. Many of the components of the required induction program are left to the district's discretion. The major change should focus on the assigning of mentors. Mentors should be assigned based on relevant experience and personality rather than seniority. Research based practices are used to educate students; the same should be done to ensure effective induction supports for beginning special educators. This can be accomplished by taking the findings from this study and conducting a large-scale survey with participants from 
across the state in general and special education. If the results of a large scale study reflect the findings from this study as well as the current research (Gehrke \& McCoy, 2007) the results can be presented to the state Department of Education to begin the process of enacting a new policy. The findings as well as current research can be used to design a new policy requiring certain levels of experience within the same field in order to be assigned as a beginning teacher's mentor.

Another implication based on the results of this study is to employ e-mentoring when a proper mentor is not available within the beginning teacher's school. Ementoring is mentoring utilizing technology when the mentor is not in the same building as the mentee. E-mentoring could be set up as a county program. A web-page could be designed that allowed communication between mentor and mentee through a chat room or discussion board. Administrators in each building could provide mentors and mentees with planning time together so they can meet via videoconference on a computer. In order to accomplish this recommendation data confirming the need for a mentor with relevant experience over a mentor in the same building would have to be provided for the county. The benefits of the program, along with the cost and implementation time should be researched. This information could be presented to county superintendents in order to display the importance of the program.

\section{Limitations of the Study}

This study has limitations that may hinder the transferability of the results. The study's limited amount of participants is the most glaring limitation. There were only six participants consisting of two beginning special educators, two Mentors, and two administrators. Due to the small sample size the results are not generalizable to a larger 
population. Also, the qualitative nature of the study allows for subjectivity, which may have resulted in researcher bias. The setting for this study was a rural district in West Virginia, which may not represent the views and opinions of beginning special educators, Mentors, and administrators in other areas.

Another limitation of the study is the inclusion of the special education coordinator as a contact person and theme. The special education coordinator was my contact person and helped recruit participants. Additionally, future researchers using these results they must be cognizant of the limitations.

\section{Future Research}

This study emphasizes the perceptions of stakeholders in a rural county in West Virginia. Future research should consist of qualitative studies with larger participant base to fully describe the process and challenges new special educators pass through from their preparation program to their first year. From these qualitative studies, quantitative studies should be designed to provide generalizable results to be used providing better supports for beginning special educators.

Additional qualitative research could consist of interviewing pre-service and inservice special educators about their expectations of their first year. These additional perspectives would allow for a richer, detailed description of the induction process. The perceptions of the two groups can be compared to determine similarities and discrepancies.

Given that each participant felt they were unprepared to meet all of the expectations of a beginning teacher, a noteworthy study would be to interview preservice teachers pre and post their first full year of teaching. The pre and post interviews 
would provide data regarding their perceptions of the challenges they will face compared to the actual challenges they encountered. Additional information could be gleaned as to their perception of their teacher preparation program as a student and a full-time teacher.

Another topic that should receive considerable attention is the assessment of induction programs. Research suggests effective induction programs promote teacher retention (Wasburn-Moses, 2006). Future research could focus on what aspects of induction promote retention and how those aspects can be evaluated to ensure efficacy.

The assigning of mentors is another important line of inquiry. In West Virginia mentors are allowed to bid on mentoring jobs with the job usually going to the most senior applicant. This contradicts the empirical support for a mentor who serves in the same field as their mentee (Gehrke \& McCoy, 2007). Future research should focus on the characteristics that an effective mentor should posses and how to best match them with beginning special educators. This research could provide data to change state policies allowing districts to assign mentors based on their ability to help a beginning teacher rather than years of experience.

Current literature suggests induction programs promote retention among special educators (Wasburn-Moses, 2006). However, the findings of this study suggest the induction program studied did not affect retention among special educators as much as the personal commitment to teach in special education. Of further importance would be to compare the retention rates of special educators who had an induction program to those who did not. Future research should investigate these phenomena further. 
In conclusion, the analysis of the stakeholders' perceptions of their induction program provided information that can add to the body of literature specifically concerning the perceptions of stakeholders. Through the analysis of data, the stakeholders perceive the induction program to have many helpful components, but still room for improvement. Mentors and administrative support from the special education coordinator were perceived to be the most important components according to the stakeholders. After analyzing the data, the most glaring aspect in need of improvement is a more efficient method of assigning mentors. Ensuring proper pairing of mentor and mentee could eliminate many of the shortcomings some induction programs suffer. Building a relationship is essential to providing an effective mentoring support, which is identified by the stakeholders of this study as the most important portion of the induction program. Whether induction supports promote retention or not, providing beginning special educators with quality induction is a necessity. Induction supports allow beginning special educators to become acclimated to their new position, learn the special education process, and provide effective instruction to help student outcomes. 


\section{References}

Amos, B. A. (2005). Defining the mentoring relationship of beginning special education teachers. Delta Kappa Gamma Bulletin, 71(4), 14-19. Retrieved from EBSCOhost.

Billingsley, B. S. (1993). Teacher retention and attrition in special and general education: A critical review of the literature. Journal of Special Education, 27(2), 137-174.

Billingsley, B. S. (2004a). Promoting teacher quality and retention in special education. Journal of Learning Disabilities, 37(5), 370-376.

Billingsley, B. S. (2007). A case study of special education teacher attrition in an urban district. Journal of Special Education Leadership, 20(1), 11-20.

Billingsley, B., Carlson, E., \& Klein, S. (2004). The working conditions and induction support of early career special educators. Exceptional Children, 70(3), 333.

Boe, E., Bobbit, S. A., Cook, L. H., Whitener, S. D., Weber, A. L. (1997). Whither didst thou go? Retention, reassignment, migration, and attrition of special and general education teachers from a national perspective. Journal of Special Education, 30(4), 371-389.

Boe, E. (1990). Comprehensive retention and attrition model (CRAM). Paper presented at the Research Forum on Differing Approaches to Defining and Measuring Personnel Supply and Demand. Washington, DC.

Boe, E. E., Barkanic, G., \& Leow, C. S. Center for Research and Evaluation in Public Policy, (1999). Retention and attrition of teachers at the school level: National trends and predictors (1999-DAR1). 
Boe, E. E., \& Cook, L. H. (2006). The chronic and increasing shortage of fully certified teachers in special and general education. Exceptional Children, 72(4), 443-460.

Boyer, L. (2005). Supporting the induction of special educators. Teaching Exceptional Children, 37(3), 44-51. Retrieved from EBSCOhost.

Brownell, M. T., Hirsch, E., \& Seo, S. (2004). Meeting the demand for highly qualified special education teachers during severe shortages: What should policymakers consider? Journal of Special Education, 38(1), 56-61.

Conderman, G., \& Katsiyannis, A. (2002). Instructional issues and practices in secondary special education. Remedial \& Special Education, 23(3), 169.

Cooley, E., \& Yovanoff, P. (1996). Supporting professionals-at-risk: Evaluating interventions to reduce burnout and improve. Exceptional Children, 62(4), 336355. Retrieved from EBSCOhost.

Council for Exceptional Children [CEC]. (1997). CEC guidelines for developing a mentorship program for beginning special education teachers. Teaching Exceptional Children, 29(6), 19-21.

Crotty, M. (2004). The foundations of social research: Meaning and perspective in the research process. Thousand Oaks, CA: Sage.

Darling-Hammond, L., \& Sclan, E. M. (1996). Who teaches and why: Dilemmas of building a profession for twenty-first century schools. In J. Sidula, T. J. Buttery, \& Guyton, e. (Eds.), Handbook of research on teacher education (2nd ed., pp. 67101). New York: Simon \& Schuster.

Denzin, N., \& Lincoln, Y. (2005). Introduction: The discipline and practice of qualitative research. In N. Denzin \& Y. Lincoln (Eds.), The SAGE handbook of qualitative 
research (pp. 1-32). Thousand Oaks: SAGE.

Dunn, L. M. (1968). Special education for the mildly retarded-Is much of it justified? Exceptional Children, 35, 5-22

Dyal, A. B., Flynt, S. W, \& Bennett-Walker, D. (1996). Schools and inclusion: Principals' perceptions. Clearing House, 70(1), 32. Retrieved from EBSCOhost.

Elfers, A. M., Plecki, M. L., \& Knapp, M. S. (2006). Teacher mobility: Looking more closely at "the movers" within a state system. Peabody Journal of Education, 81(3), 94-127.

Fagan, M. M., \& Walter, B. (1982). Mentoring among teachers. Journal of Educational Research, 76, 113-118.

Feiman-Nemser, S. (2003). What new teachers need to learn. Educational Leadership, $60(8), 25-29$

Fish, W. W., \& Stephens, T. L. (2010). Special education: A career of choice. Remedial and Special Education, 31(5), 400-407.

Flick, U. (2009). An introduction to qualitative research (4th ed.). Thousand Oaks, CA: SAGE Publications Inc.

Friend, M., Cook, L., Hurley-Chamberlain, D., \& Shamberger, C. (2010). Co-Teaching: An illustration of the complexity of collaboration in special education. Journal of Educational \& Psychological Consultation, 20(1), 9-27. doi: $10.1080 / 10474410903535380$

Gehrke, R., \& McCoy, K. (2007). Considering the context: Differences between the environments of beginning special educators who stay and those who leave. Rural Special Education Quarterly, 26(3), 32-40. Retrieved from EBSCOhost. 
Gehrke, R. S., \& Murri, N. (2006). Beginning special educators' intent to stay in special education: Why they like it here. Teacher Education and Special Education, 29(3), 179-190.

Gersten, R., Chard, D., \& Baker, S. (2000). Factors enhancing sustained use of researchbased instructional practices. Journal of Learning Disabilities, 33(5), 445. Retrieved from EBSCOhost.

Gersten, R., Keating, T., Yovanoff, P., \& Harniss, M. K. (2001). Working in special education: Factors that enhance special educators' intent to stay. Exceptional Children, 67(4), 549. Retrieved from EBSCOhost

Greiner, C. S., \& Smith, B. (2009). Analyses of selected specific variables and teacher attrition. Education, 129(4), 579-583.

Hammond, H., \& Ingalls, L. (2003). Teachers' attitudes toward inclusion: Survey results from elementary school teachers in three southwestern rural school districts. Rural Special Education Quarterly, 22(2), 24-30. Retrieved from EBSCOhost.

Henry, G.T., Bastian K.C., \& Fortner, C.K. (2011). Stayers and leavers: Early career teacher effectiveness and attrition. Educational Researcher, 40(6), 271-280.

Holdman, L. M., \& Harris, M. (2003). Special educators in a regional induction program. Rural Special Education Quarterly, 22(3), 12-19. Retrieved from EBSCOhost.

Horne, P. E., \& Timmons, V. (2009). Making it work: Teachers' perspectives on inclusion. International Journal of Inclusive Education, 13(3), 273-286. doi:10.1080/13603110701433964

Hoover, J. J., \& Patton, J. R. (2008). The role of special educators in a multitiered instructional system. Intervention in School \& Clinic, 43(4), 195-202. Retrieved 
from EBSCOhost.

Irinaga-Bistolas, C., Schalock, M., Marvin, R., \& Beck, L. (2007). Bridges to success: A developmental induction model for rural early career special educators. Rural Special Education Quarterly, 26(1), 13-22. Retrieved from EBSCOhost.

Jones, M. S., \& Pauley, W. (2003). Mentoring beginning public school teachers. Adult Learning, 14(1), 23-25. Retrieved from EBSCOhost.

Kaff, M. S. (2004). Multitasking is multitaxing: Why special educators are leaving the field. Preventing School Failure, 48(2), 10-17.

Katsiyannis, A., Zhang, D., \& Conroy, M. A. (2003). Availability of special education teachers. Remedial \& Special Education, 24(4), 246. Retrieved from EBSCOhost.

Keefe, E. B., \& Moore, V. (2004). The challenge of co-teaching in inclusive classrooms at the high school level: What the teachers told us. American Secondary Education, 32(3), 77-88. Retrieved from EBSCOhost.

Leko, M. M., \& Smith, S. W. (2010). Retaining beginning special educators: What should administrators know and do? Intervention in School and Clinic, 45(5), 321-325.

Nance, E., \& Calabrese, R. L. (2009). Special education teacher retention and attrition: The impact of increased legal requirements. International Journal of Educational Management, 23(5), 431-440.

Olivarez, M. M., \& Arnold, M. (2006). Personal and demographic characteristics of retained teachers of special education. Education, 126(4), 702-710.

Onchwari, G., \& Keengwe, J. (2008). The impact of a mentor-coaching model on teacher professional development. Early Childhood Education Journal, 36(1), 19-24. doi:10.1007/s10643-007-0233-0 
Payne, R. (2005). Special education teacher shortages: Barriers or lack of preparation? International Journal of Special Education, 20(1), 88-91.

Plash, S., \& Piotrowski, C. (2006). Retention issues: A study of Alabama special education teachers. Education, 127(1), 125-128.

Praisner, C. L. (2003). Attitudes of elementary school principals toward the inclusion of students with disabilities. Exceptional Children, 69(2), 135. Retrieved from EBSCOhost.

Prater, M., Harris, T., \& Fisher, L. (2007). Special education attrition in the state of Utah: Rural vs. urban school districts. Rural Special Education Quarterly, 26(3), 25-31. Retrieved from EBSCOhost.

Schlichte, J., Yssel, N., \& Merbler, J. (2005). Pathways to burnout: Case studies in teacher isolation and alienation. Preventing School Failure, 50(1), 35.

Serpell, Z. (2000). Beginning teacher induction: A review of the literature. American Association of Colleges for Teacher Education, Washington DC (EDRS\# 443783)

Smith, S. J., \& Israel, M. (2010). E-mentoring: Enhancing special education teacher induction. Journal of Special Education Leadership, 23(1), 30-40.

Snyder, R. (1999). Inclusion: A qualitative study of inservice general education teachers' attitudes and concerns. Education, 120(1), 173. Retrieved from EBSCOhost.

Stempien, L. R., \& Loeb, R. C. (2002). Differences in job satisfaction between general education teachers and special education teachers: Implications for retention. Remedial and Special Education, 23(5), 258-267. 
Thornton, B., Peltier, G., \& Medina, R. (2007). Reducing the special education teacher shortage. Clearing House: A Journal of Educational Strategies, Issues and Ideas, $80(5), 233-238$.

U.S. Department of Education, National Center for Education Statistics. (2011). The digest of education statistics 2010.

Van Reusen, A. K., Shoho, A. R., \& Barker, K. S. (2000). High school teacher attitudes toward inclusion. High School Journal, 84(2), 7. Retrieved from EBSCOhost.

Vannest, K. J., \& Hagan-Burke, S. (2010). Teacher time use in special education. Remedial \& Special Education, 31(2), 126-142. Retrieved from EBSCOhost.

Wasburn-Moses, L. (2006). A practical proposal for special education teacher induction. Mid-Western Educational Researcher, 19(4), 20-23.

Weimer, K. R. (2011). A survey of mentoring programs for novice K-12 teachers in West Virginia public schools. Visions of Research in Music Education, 18. Retrieved from http://www-usr.rider.edu/vrme /

Whitaker, S. D. (2000). Mentoring beginning special education teachers and the relationship to attrition. Exceptional Children, 66(4), 546. Retrieved from EBSCOhost

White, M., \& Mason, C. Y. (2006). Components of a successful mentoring program for beginning special education teachers: Perspectives from new teachers and mentors. Teacher Education and Special Education, 29(3), 191-201. 


\section{Appendix A}

Recruitment Email

Dear Mr./Mrs.,

This email is a request for you to take part in a research study regarding induction supports for beginning special educators. There is a letter attached outlining the parameters of this project, and your rights and responsibilities as a participant. Your participation in this study is completely voluntary. Your participation in this study will require you to be available for one interview, and an observation. The questionnaire may be filled out at your convenience, and an interview and observation will be scheduled at a convenient time for you. My contact information is provided in the aforementioned letter, please contact me with any questions about this process. I appreciate your time and hope we can work together on this project. I believe it will provide information that can help to provide special educators with the support to keep them in the field. West Virginia University's Institutional Review Board (IRB) has acknowledgement of this study on file.

Sincerely,

Jeremy Vittek 
Appendix B

Participant Email

Dear Participant,

Thank you for participating in this research study. I am conducting this study in the department of Special Education at WVU under the supervision my committee chairperson Kim Floyd, Ph.D., an assistant professor in the College of Human Resources and Education. Your participation will take approximately two hours total. With your permission, the audio of the interview will be recorded, and audio and video will be recorded during the mentoring session. The purpose of recording the interview is so they can be transcribed later on. The tapes will be destroyed immediately after completion of the study. If you choose to participate in this study, you will be compensated with a $\$ 50$ gift card upon completion.

Your participation in this project is appreciated, and steps will be taken in order to keep your confidentiality. All data will be reported in the aggregate. You must be 18 years of age or older to participate. At no point will you have to provide information that may compromise your anonymity. Your participation in this project is voluntary and you may withdraw yourself at any point. Your job status will not be affected if you decline this request or begin the process and withdraw. West Virginia University's Institutional Review Board has acknowledgement of this project on file. If you choose to participate simply email me and I will send you the questionnaire.

I appreciate your participation in this research study. I believe the data collected could benefit special education teachers in the future. I appreciate your time. If you have any questions about this project do not hesitate to contact me at (412)897-6844 or by e-mail at jvittek@mix.wvu.edu

Sincerely,

Jeremy Vittek 
Appendix C

Participant Questionnaire

\section{List your areas of certification in West Virginia}

2. How long have you been working in your current position?

3. Have you held any other positions in education? If so, please list each position and the number of years at each position.

4. List your current level of education.

5. List all of your degrees completed.

6. What disability categories do you currently serve?

7. What grade level do you currently teach? 
Appendix D

Beginning Special Educator Interview Questions

1. Describe the supports provided for beginning teachers

2. Describe how these supports helped.

3. Describe the stressors you have encountered as a beginning special educator.

4. Which of the stressors have caused you the most difficulties? Why?

5. What stressors are not dealt with through induction?

6 . How could these stressors be dealt with?

7. Describe your stress coping strategies.

8. What elements of your preparation program prepared you for your first year as a teacher?

9. Describe how it prepared you?

10. Were your expectations about your first year accurate?

If not, describe the main differences.

11. Describe your Mentor's role.

12. What are the most important supports for beginning teachers?

13. How are Mentors assigned in this district?

14. Aside from your Mentor, does anyone provide you with support? Describe these relationships.

15. What are the characteristics of an effective Mentor?

16. What skills should a Mentor have? 
Appendix E

Mentor Interview Questions

1. Describe the supports provided for beginning teachers

2. Describe how these supports helped.

3. Describe the stressors beginning special educators face.

4. How could these stressors be dealt with?

5. Describe your role as a Mentor.

6. What are the most important supports for beginning teachers?

7. Describe the elements of the program that you feel were the most important.

8. How are Mentors assigned in this district?

9. What are the characteristics of an effective Mentor?

10.What skills should a Mentor have?

11.How many teachers have you mentored?

12.How has mentoring changed since you began? 


\author{
Appendix F \\ Administrator Interview Questions
}

1. Describe the supports provided for beginning teachers

2. Describe how these supports helped.

3. Describe the stressors beginning special educators face.

4. What stressors are not dealt with through induction?

5. How could these stressors be dealt with?

6 . Describe the role of the Mentor.

7. What are the most important supports for beginning teachers?

8. How are Mentors assigned in this district?

9. What are the characteristics of an effective Mentor?

10. What skills should a Mentor have?

11. How are Mentors assessed?

12. Describe the supports administrators provide Mentors. 


\section{Appendix G}

Transcriptions

\section{Triad 1 Teacher Interview}

Jeremy Vittek: Describe the stressors you have encountered as a beginning special educator?

Teacher1: The paperwork and the IEPs that are online, um it's difficult to keep track of the order in which the paperwork needs to be filled out and turned out and you have to wait so many days before you can take the next step. I think that's been the biggest thing. Just trying to get that all straightened out and to find a system. Also, I guess trying to find the material, know what would be the best to help this student. There's so much out there it's just hard to pick and choose.

JV: You mentioned the online IEPs, did you have any experience with that prior to coming here?

T1: I did actually, we didn't do online. We did just the regular format I guess it is. So not the online version. So I had a little idea of what to expect, but as to navigate the program in itself it can be difficult.

JV: Which of stressors have caused you the most difficulties and why?

T1: The paperwork. Just making sure everything is filled out the way it needs to be and says what it needs to say.

JV: What kinds of supports are you provided to help you with those stressors?

T1: The Mentor program is nice because I do have somebody and it worked out that my Mentor was actually in this position I'm in now last year. She did that for I believe the last five or seven years so she was able to answer a lot of my questions and she's just kind of nice to have on speed dial. I can call her any time. She's wonderful at being able to answer and help me. (Special Education Coordinator) is always easy to contact, so that makes it nice.

JV: How often do you contact your Mentor and (Special Education Coordinator)?

T1: At least a couple times a week. I'm in touch more with (Special Education Coordinator), but my Mentor I talk to her at least probably every other day. Just sometimes with the little questions and just to double check something. When I call her it's spur of the moment type thing.

JV: How often are the scheduled mentoring sessions? 
T1: The actual sit down mentoring sessions when we talk about certain topics, I believe it's one a month. I feel like I see her so much it's hard to keep track of what they require and what she does extra for me.

JV: Are there any stressors or challenges that are not dealt with through the induction program?

T1: I would think that would be trying to find the appropriate material. There was, like I said there's just so much out there and it's hard to pick what is best for your students. And you do want to help all the kids. They are all kid of being challenged, things like that. You just, for me I didn't know where to start.

JV: Is that something that you would ask your Mentor about?

T1: I did, I would ask but like I said she was in that position before me so she kind of had her system set up. I have tried to follow kind of what she did with them, the schedule, what she expected of them up to a point. But I'm finding now some of the things aren't something I think I want to continue with next year. I'd like to incorporate some new materials. Um, starting to forget where I was going. What was the question again?

JV: What stressors aren't dealt with through induction?

T1: Ok

JV: The follow up is how could that be dealt with?

T1: I'm not sure how that one would, cause I guess it's just a personal preference. And everyone would have a different answer where they think that those students should be and what goals they should meet and how they should maintain it.

JV: What elements of your preparation program prepared you for your first year as a special education teacher?

T1: Just having someone that you know that you can call and contact and be able to answer those questions that may pop up out of nowhere. It's just nice knowing they're just a phone call away.

JV: What about the coursework you took in college, what part of that helped prepare you for your first year as a special educator?

T1: They were big on saying kind of expect the unexpected. No two days are going to be alike. Especially in special education you need to be flexible and just willing to go with the flow. I think knowing that ahead of time helped a lot. There are days when you have a schedule and you know what you want to get done and there's a million things going on throughout the school and sometimes you just have to push that to the side and get done what you can and hope to make up for it the next days. 
JV: Could you talk a little bit about the coursework and field experience and how that helped if at all for your first year?

T1: I was actually on the other end of special education for all my observations. Gifted is not where I ever really saw myself. So I can't say any of my observations have helped with that. I did take two online gifted and talented courses and I think it helped me realize these kids still do face problems. I mean not everything comes easy for them. There's things you may think that they automatically get and I find myself realizing, ok no you do have to take a step back. They still are kids and they don't always fit that stereotype that they just get it. They still have to work at some things to.

JV: Can you describe your expectations for your first year?

T1: I didn't know what to expect really. I didn't know anything besides where the school I was going to be at, my Mentor actually helped me. All my IEPs, not all of them, most of them were due before I even got to meet my students. So to actually write IEPs for students I didn't know, that was difficult. So my expectation was just kind of go by what she had and kind of keep to that schedule and I have a notebook that I've kind of jotted things down. Things that worked, things that didn't work. And that way this coming summer I can look at that and decide what I want to do. What do I want from them?

JV: Can you talk about how accurate your expectations were?

T1: I think I made the right choice of not trying to start from scratch. I, I used a lot of the resources and things that were made available that way I could concentrate on getting to know the students and kind of see where they should be and how it is I can challenge them without overwhelming them. I still think I have a lot of that to learn, because there are a lot of times something I think they may get really quickly and will be super easy for them, we spend the most time on. Some things I think may be challenging to them there are times we have gotten through it really quick. I wish in field work that I would have had more experience with kind of knowing where an average student should be at a certain point. They help to a certain extent. It would have been nice but I'm not sure how you would get that experience, I think it comes with years of teaching.

JV: What are the most important supports for beginning teachers?

T1: I think it's important to have a Mentor, whether it's an official Mentor or just someone you can rely on or count on to kind of walk you through when you run into those obstacles. Someone who may have faced the same issues. May have been in the same position or just have the experience and it's nice that the principals to be helpful. That's a big thing. I've been lucky at both schools that I'm at the principals have been helpful and supportive. I know if I need something I can go and ask and they'll help me the best they can. If they don't know exactly how to answer it they're able to direct me to someone who could. 
JV: You mentioned the Mentor as one of the important supports. Could you describe your Mentors role?

T1: Oh, in one word she's amazing. She's always there, she's very reliable, she's consistent. There's never been anything she's you know kind of left me hanging on. Just like the principals, if there's something she's not really sure how to answer she always knows the contact and double checks on it to make sure. She's just, she's been amazing this whole time. I'm not sure how I would have survived the first year if it wasn't for her.

JV: Can you describe your interactions with your Mentor?

T1: They are usually pretty laid back. She'll call and check in a good bit just to see how things are going. Like if I don't call her she'll usually will call and say hey I haven't heard from you in a while is everything going ok. The formal mentoring when we meet, she'll go over things she feels are going to becoming an obstacle for me. Like, um, the West Test things like that that she knows are coming up. We'll sit down and talk, like do you have any questions about this, this is how I handled these situations. Here are other options, so she kind of prepares me before I get thrown into that mix.

JV: Do you know if that is put in place, or is that how she decided to go about it?

T1: See that I'm not too sure of. I know there are some things, like when we sit down we have to fill out a paper of how long we talked, what it is we talked about, things like that. But I'm not sure if she's told what to pick and choose or if she that's just her ideas. That I'm not sure of.

JV: Do you know how Mentors are assigned in this district?

T1: I believe they try to get you someone who is at your school so it's more convenient to try and set up meeting times. But, in this case since she was the last person in this position I believe that's how we got paired up with one another. If I'm thinking correctly there wasn't another Mentor at my school at the time.

JV: Do you find difficulties with your Mentor not being in your school?

T1: No, I could see that for maybe other cases being an issue but for us it's not. Just because she's been so open and I have her cell phone number I have a million ways I can contact her and she's always been ok with that. No matter what time, whenever, I can contact her very easily.

JV: Does anyone else provide you with support?

T1: Other teachers, they are all very helpful if I'm having an issue with a specific grade level I can go to any of those grade level teachers and kind of ask for advice or do you have any resources that you may not be able to use in your classroom that you feel might 
benefit these students. I've not ran across anyone that was not willing to help, so I've been very lucky with that.

JV: Could you describe how some of these relationships started?

T1: Um, that was a little rough and still at some times I get more shy approaching them. I think I was very lucky getting hired on right out of college. Sometimes you feel they kind of look at you like you're too young, how did you get on so quickly. But, they're, that changed right away. They are all very warm and welcoming. No one ever made me feel uncomfortable. I think I thought in my head, I mean no one ever did anything to make me feel like they didn't like me or didn't want me there. I think it was just part of my insecurities.

JV: What are the characteristics of an effective Mentor?

T1: I think they need to be someone who's flexible, organized, reliable, patient. That's a big one. They just need to be there for the right reasons. They need to be there to want to help you otherwise that could be very overwhelming for them and I guess us or the person they are mentoring.

JV: How important do you think that person's background is, to being a good Mentor?

T1: I think right now years of experience kind of exceeds anything, cause I think I feel the longer you do something the more you get to see. So the more options, I guess it's more likely for them to come across that you may be experiencing. As far as the position they held, you can relate to other people in different positions. But it is nice to have someone who has already walked in your shoes.

JV: What skills should a Mentor have?

T1: Again I think they need to, I guess all the things I said as part of the characteristics. They need to be good at communicating. Just giving you different ideas and options and just being able to talk to you about things. Just being comfortable with sitting down and having a conversation and it not having to be specific to maybe what they are told to cover but just meet the needs of whatever that person needs at that time.

JV: Can you describe the orientation supports you were provided?

T1: My Mentor was the biggest support for that. I came in, you have a few weeks. Not a few weeks, well I guess you have the option of having a few weeks before the students come to come in and get your classroom set up and all that. I think everyone was helpful from the start it was Lori my Mentor and then from there the principal. He sent out a nice welcome letter, let me know when you know people were going to be there to get things ready. If I needed anything I could contact him the first day I came he was who showed me where the room was if you need anything moved these are the people you contact. I guess finding the resources and if I had specific questions to let him know and he's been 
a big help to I can contact him anytime. The custodians, maybe it was more of a gossiping thing but they could tell you these people will really help you, these people eh, they'll help you but maybe ask one of these guys first stuff like that. So it was a nice first couple of weeks before the students come just to kind of interact with the other people in the school system.

JV: Was there anything at the beginning of the year that you didn't know how to handle?

T1: I still feel like that a lot. There are days where I'm kind of like, I do pay attention it's like why does this not sound familiar to me. I think it's just everything is so new right now. They always, well what I've been told, once you get the first year under your belt it's kind of a new ballgame when you go into your second year. You kind of know more what to expect, not that next year is going to be the same by any stretch, it's always going to be different and change. At least you have one year under your belt, but as far as just different duties that there are and expectations, just kind of the extracurricular things that go into it as well.

JV: Could you describe what you mean by the extracurricular activities?

T1: Um, like the different competitions and contests. Helping to prepare the kids for that. Like faculty senate things coming here to new teacher orientation and also for the articulation team meetings for the special educators and also this was just by my choice but doing the home bound and tutoring.

JV: How has the induction program increased your job satisfaction? Or has it?

T1: It has, it's nice to be able to come to these meetings and you're in a group full of people who this is there first year. It may not necessarily be their first as a teacher but it's their first in the county and even though they have seven or fifteen or however many years they still have questions too. It kind of sets your mind at ease there, that you're always going to have questions. It's ok to not always have the answer. You have a group full of people that they're having the same feelings and emotions that you are.

JV: Can you describe the new teacher meetings?

T1: Um, they are fairly casual and laid back. Each month is something different. We've had workshops, we've had just parents come in and talk, we've had other teachers come in and talk. The first few were kind of icebreakers, activities and things like that. It was nice cause it gave you ideas on how to get to know your students better as well as other people in your building. It's always different and you always leave with something.

JV: Are all the activities specifically based on beginning teachers?

T1: Yes, well maybe not just beginning teachers but one example is they had there's a new math series in the county and it's something they started maybe two years ago and 
they had a workshop on that. How to find the materials, how to use the book, things like that. What do you do if, type thing.

$\mathrm{JV}$ : Has the induction program increased your intent to stay in the field of special education?

T1: I wouldn't say that. Um, I love what I do. I don't think I would ever want to go to general ed and I think it's just more because all my observations and field training has been in special ed. Even though the paperwork is a lot and it's not all that fun, it's still worth it. But I wouldn't say these meetings have influenced that either way.

JV: Is there anything that would cause you to leave the field?

T1: I don't know. In my mind right now, no. But everything is so new. So I would love wherever I was. I just always wanted to work with kids. That's all really I ever wanted to do so I met that. Um, it's just right now I have the luxury of being on both sides of special education. During the day I'm working with the upper end with the gifted and talented students then in the evenings I work with boys with autism. So I don't feel like I've neglected either.

JV: Do you have any stress coping strategies you use?

T1: I just like to talk to other people and get their feedback. It's nice to be able to run your ideas and thought process by someone and have them agree with you or maybe step in and say I wouldn't necessarily try that but here's a good idea. It's nice to be able to bounce ideas off people. Also, making a list of things that I know are coming up and make notes about how something may have went a lesson, or a meeting, just jot down different things that come to mind. That way I can look back on it and go from there.

JV: Is there anything you would like to add or do you have any questions?

T1: I think it's nice that they offer it, I'm not sure about other counties but it's nice knowing here you have that support system. I've had good support systems clear through I mean I wouldn't change, I wouldn't say I wouldn't change anything, but as far as the people around me and what they've done to help me in this first year I wouldn't change any of that. 


\section{Triad 2 Teacher Interview}

Jeremy Vittek: Describe the main stressors or challenges you face as a beginning special educator.

Teacher2: Um paperwork and uh IEP's that aren't very detailed, students you don't know. Um, making your own schedule. We are working now with our counselors to create our schedules with them instead of trying to fit ourselves into classes.

JV: Why do you have to make your own schedule?

T2: Uh, we have to make our own schedules to um meet all the students needs. Like to know where we need to be during specific times. A lot of it is co-teaching. I only have two self-contained classes. So the majority of it we have to fit ourselves into the classes with the students that need it the most.

JV: How do you go about figuring out where you need to be? Was there a schedule given to you at the beginning of the year?

T2: We have to go through every single students' schedule, figure out where they're at then go from there. So, about forty some students you have to go through and figure out that, so.

JV: Is that something you were told you needed to do at the beginning of the year?

T2: Nope. It wasn't until, we didn't have a Mentor at the beginning of the year. Uh, the other teacher in there she kind of played as our Mentor but even she's kind of out of date on what's going on.

JV: Which of the stressors or challenges have caused you the most difficulty and why?

T2: Uh, paperwork and getting ready for this audit that just came up cause it was I think the five years was up for the audit we just had. So getting all that together making sure all the teachers were on task to, um, because paperwork that I don't know really.

JV: Can you describe the audit a little bit?

T2: The audit they came in to see if we were we met the minutes that were required on the IEPs so we had to go through and make amendments to every single students' IEP to make sure they matched with every single minute we were with them. Like our schedule had to match their schedules and the minutes we were with them. So say I'm in a class two times a week, I had to match up my time, and we have the block schedule too, so we had to figure all that out. They came in, made sure all that matched up. They talked to us about um our monitoring of students and how we like keep track of it. So we made everyone in the school do a modification calendar to keep track of what they're doing and 
what we're doing. They interviewed us, they interviewed regular ed teachers, they watched us in the classroom.

JV: Can you describe the supports that you're provided as a beginning teacher?

T2: (Special Education Coordinator) is our main support, um, uh supports at the beginning?

JV: Sure, you can start at the beginning.

T2: There wasn't a whole lot, um, we had the other teacher in there. But like I said she didn't have, I mean she had information, but it wasn't what we needed cause everything is up to date now and the Mentor that we have taught special ed maybe a few years and she teaches PE now. And, can't really go to her for questions. Um, uh the principal, he has a son who receives uh services so he knows some stuff but like I said we are basically there winging it. And if we just the other special ed teacher just switched over the math, like you said, they leave pretty quick. So she switched to math and now we're currently trying to figure out who we're going to get.

JV: Can you describe how the supports you received have helped you?

T2: Um, (Special Education Coordinator)'s very helpful. All I have to do is shoot any email to (Special Education Coordinator) and she'll respond right away. Like what supports are you looking for?

JV: I don't want to lead you, I can say you did mention (Special Education Coordinator) as a support, you mentioned the principal. So if you just want to describe in more detail how they have helped you.

T2: Oh, like if there's a process I don't know because um I am in my first year in the high school special ed like uh, she talked me through the IEP like when I'm doing a meeting and that kind of stuff. And the counselors have helped me out in that area as well. Um, so I don't feel like we've been taught fully what we need to do before we even go in there. Like all that paperwork and the meetings and the IEPS are new too, because it's all computer based now. So basically I'm teaching the other teacher how to do an IEP on the computer. The supports through (Special Education Coordinator) she just, like I said, she'll answer any question. Like, um, there's a manifestation that we had to do so she helped me out with that, so.

JV: Can you describe that process a little bit? Obviously not the specifics about the student, but how she helped you.

T2: It wasn't actually my student, but I asked that we figure something out with him. So, we had a meeting actually today. With the parent to figure out the steps we need to take. So we put him in an alternate setting, and um uh we're currently trying to work with him to work with us. 
JV: How did (Special Education Coordinator) help make that process easier?

T2: She came in and talked with us I think it was last Friday about what we could do and in place of just kicking him out. Um, so she came up with the idea of doing the alternate setting, we have kind of a teacher that comes in and works with some students who are in an alternate setting already. So we are putting him self-contained those periods that he's getting in trouble. To show that we are making the steps um, if something happens. It can show that we tried. I don't feel like I'm answering your questions.

JV: No, you are doing fine. There's no wrong answer, these are your perceptions. Can you talk about which stressors aren't dealt with through induction or the different supports?

T2: That aren't dealt with?

JV: Yes, if any.

T2: Um, our other principal. He does a really good job like if we have any concerns with behavior. He's always trying to help out with that but, uh like the classroom that we're in that's not really being met with. We don't have enough classrooms so everyone is in the same class. There's a student who's in there the whole day, then we have to have our self-contained classes in there, so it's very distracting to myself and the students. So I don't feel like that's something that they can really fix, but with the new school hopefully. Cause we are getting a new school, hopefully that will be fixed and dealt with. Um, just there's really no one to go to to ask questions basically. I know (Special Education Coordinator)'s not always available to ask. If ike just specific questions are hard to get answered sometimes.

JV: Can you describe or give an example of these types of questions?

T2: The other day I had to ask the counselors and the principal um, are students with an IEP allowed to receive zeros or an F on their midterms or report cards. No one knew. And it was like after school so the only that's when I actually text her later that day to find out what to do about students who aren't doing their work and that's what that meeting was about. I mean I finally got ahold of her, but when I needed to know there was no one there. Um, what else? Uh, trying to think. Not sure, there's a bunch of questions that I've had. I just can't think at the moment.

JV: If any come to mind we can come back to this question. Can you describe any stress coping strategies that you use?

T2: Walk away. I work out now. I just I coach basketball too, so. Um, that was a way to get away. Now that everything is over it's starting to calm down. Coping-wise, um sometimes you just got to walk away like I said. Maybe not the best method. 
JV: What elements of your preparation program in college, prepared you for your first year as a special educator?

T2: I think field experience helped me more than anything. Especially when I was student teaching, I did four different placements. I think those helped out a lot. Um, I think course work was a lot of repetition, yes I know who Piaget is, but I think mainly my field experience rather than the coursework, cause I think some of the coursework should have dealt with more of the IEP and paperwork than what they did teach us.

JV: Can you describe how the field experience did help?

T2: Just cause you got to get in there, hands on and actually teach the students the methods you did, like I did learn things from the coursework like strategies and everything that I use in the classroom now. It's um, but like I said that was more towards my student teaching rather than those classes before hand. Um, but in the field you're able to use those strategies, see what works what doesn't work, and go from there.

JV: What were your expectations coming into your first year as a teacher?

T2: Um, madness. I knew it was a new program, I knew that it was going to be touch. Basically we were building the program. Um, I knew there was going to be a lot expected and basically I was informed that I was going to have to kind of be the head of it, which I didn't want to because I needed someone to lean on too. Um, what I expected? Not so mouthy kids.

JV: How accurate were your expectations?

T2: Oh, it's madness. It's getting easier as it goes but there's still days when you just want to throw in the towel.

JV: Can you describe your Mentor's role in your induction?

T2: My Mentor, now? She comes in and sees me once a month and signs some papers. She stops by and asks if there any questions concerns, anything she can help me with. She can't really help me if she doesn't know herself.

JV: Can you describe the interaction between you two?

T2: She's very nice, don't get me wrong. I'm not saying she doesn't try to help. Like, process of behaviors or what I need to do in a situation or um paperwork and stuff like that, not real sure. Um, she'll offer to help me out in the class every, doesn't really amount to much.

JV: How often do you interact with your Mentor? 
T2: Every Wednesday she comes in and has me sign papers. I see her every once in a while and she asks home I'm doing. She's I mean she's there for me support-wise.

Making sure I'm not too stressed and everything. But, uh, but not having someone that I can actually go to and show me how to do this is frustrating.

JV: When are your actual Mentoring sessions?

T2: What mentoring sessions?

JV: There aren't set aside times?

T2: No, like PLC's she'll sometimes ask then but I don't think that's set aside for mentoring sessions. I don't believe. Um, that's supposed to be for the students getting things ready for that. She'll ask and everything and take note of stuff that I'm concerned with. Other than meeting, we've never really had just a mentoring meeting.

JV: So when she comes in on those Wednesdays will she come in on your planning time?

T2: It's called PLC, I don't even know the breakdown of it, we meet in the morning. We break up into our programs, like special ed programs, math, science. So everyone is in there, it's not just me. So it's like everyone in special ed like the three teachers and then for some reason sometimes the driver's ed teacher is in there, I don't know.

JV: In your opinion what are the most important supports for beginning teachers?

T2: Someone who knows what they're doing. Um, who knows the process, and um who's there for questioning. Um, I think to bounce ideas back and forth. Um, I don't know.

JV: So you think the mentoring is the most important?

T2: Yes, I think that support-wise it would be good for trainings on like the whole process of IEPS, the whole paperwork. I keep bringing up paperwork, but that's all special ed is. Um, like having uh training on that kind of stuff would be very helpful for first year teachers Like, I got training for Kansas writing at the beginning. Someone was willing to come in and teach me some of that, cause I was in a classroom where I had no idea what Kansas writing even was. So I asked (Special Education Coordinator) for some training in that.

JV: So professional development?

T2: Kind of, there's been professional development but it's been more for computer grade book kind of thing. Not really any thing related to us. Which everybody needs that, um. Trying to think.

JV: How are Mentors assigned in this district? 
T2: No, I think they bid on it.

JV: Aside from your Mentor does anybody else provide you with support?

T2: Uh, there's another teacher who worked in special ed for a long time and now he just teaches social studies and history. He's always there and he even gave me a book on behavior, like what to do. If I have questions he's pretty good about helping me out with that.

JV: Can you describe how that relationship started?

T2: Um, we are in the same building and he comes in and to our room sometimes. We're just all in the same building. If you knew Cameron, Cameron is like this big (making gesture for small) you'll see when you come. But everybody is really close there. There's the librarian is a pretty good support. She used to teach now she's the librarian. Like if I have questions about specific students she's pretty good about saying she'll work with them if they're being a behavior problem and that kind of thing.

JV: What do you think are the characteristics of an effective Mentor?

T2: Knowledgeable, um um someone who actually is going to try to help you out. Not someone who's just getting a paycheck for being a Mentor I guess.

JV: What skills should a Mentor have?

T2: The skills they are mentoring in. Um, like I understand that she had a special ed degree at one time, my Mentor, but I think she taught it one year then did PE the rest of the time. She has the degree, but not the experience as well. I think they need to have the experience as well as the knowledge. I don't know if that has anything to do with the question.

JV: It does. So you think years experience and knowledge two of the most important skills?

T2: I couldn't be someone's Mentor next year. I would have to have more experience of what to do in certain situations and to deal with those type of situations.

JV: How long would it be before you were comfortable being someone's Mentor?

T2: Long time, long time. Um, not right away. I think good experience is cause you probably have so many things, five ten years plus, I don't know. Not one or two years in because there's so many different scenarios.

JV: How has the induction program increased your job satisfaction? If at all?

T2: I guess, I don't know. Um, what do you mean by induction program? 
JV: The supports that you're provided.

T2: Like I said, I've been ready to throw in the towel and find another job but I'll stick it out. Um, at times it's good at times it's bad. Just depends on the day I guess. Um, I knew going in to the job that I wasn't going to have the greatest supports so I guess just try and figure it out.

JV: Why was it your perception that you weren't going to have good supports?

T2: Because I knew who worked there because the other teacher was a new teacher as well. Same as me. The teacher that is in there who does the self-contained class all day she has one student but uh, she's I knew her from when I went to Cameron. Um, and I knew that there was no one else, as head of special ed out there. Basically I was told that I'm going to be in the that position in the next couple years. I don't know if I'm ready for that.

JV: So has the induction program and supports you were provided increased your intentions to stay in the field? If it has.

T2: I enjoyed working in special ed, I'm not going to leave it. I miss little kids, but um just I've grown to like working with those students so um I'll stick with it until, until things change I guess.

JV: What factors could lead you to consider leaving the field?

T2: Um, like I said I miss working with younger students that my real passion. Um, but I like working with students in special ed still. If there was something of that sort to come up, or um anything I don't know. Uh, just better, sometimes the working environment isn't great, but that's every work environment. I don't know if that would change it or not.

JV: So it sounds that even though it is a struggle you are committed to special education.

T2: Yeah, that's what I do.

JV: The questions are finished. Do you have any questions or final comments or thoughts?

T2: No, hopefully I answered what you needed.

JV: You did great. 


\section{Triad 1 Mentor Interview}

Jeremy Vittek: Can you describe the supports provided for beginning teachers?

Mentor: In (School Name) County they get a Mentor obviously and there's a series of I don't know, I think it's twelve new teacher um meetings. The ones we covered when I was hired was behavior and different stuff like that. Um, that's what's supposed to happen. Then you have some people who bid on Mentor jobs and don't do anything. I mean total honesty there. We just had a conversation about one the other day. I mean she's done nothing all year, they even changed the posting this year. Um, cause they had a couple people last year who didn't do what they are supposed to do. Come the end of the year they are scrambling to do all the paperwork. So now in order to get paid, you have to turn your stuff in monthly. And there's a young lady, er lady who hasn't turned anything in all year. So, yeah. So she's not getting paid.

JV: Could you describe how these supports help beginning teachers?

M1: I think at least, I mean this is my first time being a Mentor. Um, when I was, when it was me that had the Mentor it was just somebody to talk to, somebody to bounce things off of, somebody who'd been there. Um, and I hope that (Teacher 1) feels that way. Some of the different training, you know were relevant. I don't, at the time I was teaching gifted so I didn't realize how relevant. Now that I have to deal with behavior issues, I pulled out the old binder the other day.

JV: Could you describe some of the stressors or challenges beginning special educators face in their first year?

M1: I think it's more, the biggest is time management. They're trained to be in a classroom, they're not trained to figure out how am I going to do sixteen IEPs in the Fall or in the Spring when I'm trying to teach and do all the stuff. How am I going to coordinate everybody's schedule to the necessary people are there. That kind of stuff.

JV: How could these stressors be dealt with?

M1: Um, that stirs up the kettle. Basically because there are two schools of thought in (School Name) County. Most everybody does Spring IEPs which gives you more time to prepare. I do Fall IEPs and God love (Teacher 1) she inherited all of mine. One of the things we did do and again, because of who our special ed director is, she gave us a day over the summer and (Teacher 1) and I went down to the county office and sat together and wrote all of her IEPs for this year. So, it depends on the specific situation.

JV: Could you describe your role as a Mentor?

M1: A lot of different things. I think it's like being a special ed teacher. You're a friend, a coach, you're a confidant. You know, um, I don't know. (Teacher 1) and I have it different because we just hit it off. It's different too because she's in the job I left. Our 
relationship is a whole lot easier because I'm not trying to tell her how to do a job that I've never done.

JV: What do you think are the most important supports for the beginning teachers?

M1: The confidant, the friend. Someone to give them how do I want to put this. Unbiased advice. So...

JV: Could you describe the elements of the induction program that you feel are most important?

M1: Probably the Mentor. I don't, like the trainings were okay but after a while they got repetitive and you heard the same thing over and over. Having that person, I guess how do I put it. Having that person that is yours, you know you can call them and you know you're going to get a straight answer and it's someone you can trust.

JV: How do you think that trust is built in a Mentor mentee relationship?

M1: (Teacher 1) and I had a different um, but I think that trust is through you know that you what you have these questions I'm not running back to your principal and saying look she doesn't even know how to do this, that's what I'm here for and I think you have to show these beginning teachers that that's what you're here for. That you're not there to judge them, you know.

JV: Do you feel a Mentor mentee Mentor relationship can work without that trust you talked about?

M1: No, it's useless. I've watched it. I've watched last year I watched a young lady her Mentor did absolutely nothing with her, there was no trust established. She did it on her own because she had an unofficial Mentor who took her under her wing but the women who got paid didn't do anything for her.

JV: How are Mentors assigned in this county?

M1: Um, various ways. Well I guess I shouldn't say various ways. The job is posted and then, it used to be they were totally decided by seniority. Now, one of the things they take into account is if you've ever been a Mentor in the past and if your paperwork was late or not done. They also take into account certifications. Like I said with (Teacher 1) and I it was a no brainer it was my job. So you know, um and that was there was actually someone who was upset that she wasn't picked as (Teacher 1)'s Mentor.

JV: So your mentee is not in the same building as you at all?

M1: No she is not, she does an after school thing here, but that's it. But (Special Education Coordinator) gave me at the beginning of the year I had, five or six half days to go spend with her. We spent some time over the summer you know, it's just now that 
we gotten to the point where we meet for dinner after school. So I would go see her at the beginning of the year.

JV: What are the characteristics of an effective Mentor?

M1: Think you have to be open, honest. Um, you have to be trustworthy. You know, these kids are coming out I remember and I was older when I graduated. I wanted to appear completely confident, or completely competent and you know, well I don't want to ask that question it's stupid. These kids need to see that that's what we're here for. And I will say I think (Teacher 1) does, you know, she it's we do a lot by text, but she's not afraid to say look I know you explained this once but can we go over it again?

JV: What skills should a Mentor have?

M1: Personally I think the Mentor needs to have taught what their mentee is teaching. I know that's part of your thesis here and I'm just going to tell you, if I were trying to Mentor, if I weren't a special ed teacher and was trying to Mentor a special ed teacher I don't know how you do it. Because if you're not doing the paperwork and somebody's got a question on the paperwork how do you answer it? Even on the other hand, I would never bid on Mentoring a general ed teacher, I've never done it. I don't know what I'm doing. My gifted job was pull out, so I've never had a class for more than fort-five minutes. Up here, you know, okay look, everybody's having a bad day kids are cranky we're going to sit down and play a game or play a movie. I can't do that with twenty kids in a room. So I would never attempt to Mentor a general ed teacher.

JV: So do you think that is a state level issue because of the policy that requires a Mentoring position to be posted?

M1: Yeah, if that is where it comes from then yeah. Because if I don't have that experience how am I going to guide her? I guess that's the bottom line.

JV: Do you think it would be more valuable to have a Mentor within the same field and communicate electronically?

M1: Absolutely.

JV: How many teachers have you mentored?

M1: This is the first one. I'll be honest I asked for the training because I wanted to be (Teacher 1)'s Mentor.

JV: How has mentoring changed since you were mentored?

M1: It was actually this same situation. So I can't say the situation changed much. It was another gifted teacher who was not in my building who was given time to come down to my building. Um, I don't know that it really because I trusted my Mentor. I don't know 
that it really has, I think again, and this is kind of you know backing out of the questions but it depends on the people involved. It depends a whole lot on personal qualities.

JV: Do you think the induction program promotes retention among special educators?

M1: I think it depends on the person. Because and it's funny that that's a questions because we have talked about this. When I started teaching in (School Name) County bid into special ed bid out to regular ed, get out as fast as you could. Now seven years later we've the county has hired a lot of special ed teachers who are not going anywhere. I don't know that the Mentor relationship or the induction program had anything to do with that. I think it's the personal qualities. These people have wanted to be special ed teachers all their lives. We joke, I'll die a special ed teacher, (Teacher 1) will die a special ed teacher. I don't know that the induction program has any, I think the induction program has more to do with how effectively they do their job or how much they know about paperwork and that kind of stuff. (Teacher 1) and I sat down this summer and wrote IEPs. We sat down another couple hours and went through every piece of special ed paperwork there is.

JV: Could you talk about what you attribute the hiring of teachers who plan to remain in special education to?

M1: Um, wow. I'm going to just throw it out there and be completely honest. I think a lot of it has to do with our special ed director. Right now in (School Name) County (Special Education Coordinator) is the best one to work for and that word has gotten around. Part of that I guess, may be due to some of these teachers have been hired recently. Special ed teachers had (Special Education Coordinator) when she was teaching at West Liberty or Bethany. That may be. She had a lot of these kids. In fact I had a young lady in my room a little bit ago had an interview for another gifted job yesterday, she was a former student of (Special Education Coordinator)'s. A lot of these people have had her. She is an amazing woman. She's a good judge of character as well. I think it has to do with her ability to read people. She's had an impact.

JV: Is (Special Education Coordinator) a part of the hiring process?

M1: Most times when there is a special ed interview she is on it. When (Teacher 1) got hired (Special Education Coordinator) was on the committee, the principal, and I. Again because it was my job. I knew what it took.

JV: Do you feel that preparation programs prepare special educators for their first year?

M1: I don't know about now. I'll give you a little bit of when I went through I never had to write an IEP. When I got out and I had to write my first IEP, thank god that I had made some close contacts with teachers at John (School Name) because they talked me through everything. I got thrown into a long term and they were like this IEPs due. I think some of that changed again, I worship her, um some of that changed when (Special Education Coordinator) started teaching in the colleges because I actually took a behavior class with 
her. So I actually had to write a functional behavior assessment and I had to do what a teacher is going to have to do. (Teacher 1) and I have never really talked about that as far as what she had to do but I can't tell you now. But when I was still taking a couple classes and (Special Education Coordinator) was the professor, yeah. I know another girl is taking a master's program, but she has had to write I think a behavior intervention plan and different things. So, do I think there doing a 100\% probably not, but they're getting better. Because I had no clue when I came out.

JV: So you think anything with practical application is more important?

M1: I think it has to be, because I sat through a lot of classes. You know what, give me theories all you want, it's not going to help. Give me a couple templates like I just got done writing my first behavior intervention plan, seven years never had to do one. Basically I called (Special Education Coordinator) and said send me every template you've got and I have a couple here. I put them all together and made my own because that was what was going to work for me. Give these kids that, let them you know, let them go for special ed teachers I think they need to see more than anything else. People have this vision of what a special ed teacher's going to be, then people walk in and say really? I'll tell you what, this job I'm in now I couldn't have done my first year. I got one who an turn on a dime. Can be the sweetest little thing, next thing you know she's on the floor throwing a tantrum. I'd a never been ready for that and I started when I was twenty nine, let alone a twenty-two year old kid. I'm rambling.

JV: Do you have any other comments or questions on the process?

M1: I know it's getting better under (Special Education Coordinator). A lot of it used to just be fly by the seat of our pants, you know she's probably the only special director, at least that I know that every special ed teacher has her cell phone number. There are days I text her at five in the morning, may have to wait a little bit but you'll get an answer. She's the best thing to happen to (School Name) County special ed, and now I'll shut up. 


\section{Triad 2 Mentor Interview}

Jeremy Vittek: Could you describe the supports provided for beginning teachers?

Mentor: In general?

JV: Yes

Mentor: Ok, by support you mean?

JV: Uh, maybe induction program, basically when a beginning teacher starts in this school district or county what are your perceptions on the supports that are provided, could you describe them.

M2: Well I think they have an advantage in the special ed because of Dr. Haines is good. She kind of took care of making sure they had everything they needed if there was something they needed to know specifically about special ed, she took care of it. So that would probably be my answer. They might be a little different than just the regular ed teacher, they get extra support.

JV: What are the stressors or challenges beginning special educators face?

M2: It's a whole different world than a regular ed teacher. They are dealing with a variety of students with a variety of needs and you have to try and get to know that student. I thought they are thrust into it to be honest. They are like here, this is what you got to deal with. And trying to get to know the student plus do the testing that needs to be done, and follow this student up for resource time. I think they are bombarded by just too much to do.

JV: How could those stressors or challenges be dealt with?

M2: I think they have a strong support system on this staff. Mostly the administrators, and I'm there. I always offer, anything you need and I've been there forever. Um, and I can step in if you need. You need someone to go follow a student I'll gladly go do that. I think they have a strong supports system from the administrators and myself.

JV: Describe your role as a Mentor.

M2: Um, I think that, I feel that it's a support system. Mostly. Because I think the traditional person that is in a regular ed classroom, mentoring that person and mentoring someone in special ed are two different ballgames. I try to help them with you need to get to know that student better, if you need to make contact with a parent, if you need me in on a meeting. I do that sort of a thing. Um, making sure that they've followed up and are doing everything according to the law. There's behavior issues you have to deal with and sometimes they might ask me a question about a specific student you know. You've been 
around that student for $\mathrm{x}$ amount of years, you know them better tell me a little about them. I'm more of a liaison to them.

JV: What are the most important supports for beginning teachers?

M2: That's a tough one. To try to make them feel capable of , that's a hard question to answer.

JV: Do you want me to come back to that one?

Mentor: It's mostly because it's special ed and I feel like that's a different world. Ask me again.

JV: What are the most important supports for beginning teachers?

M2: To help them like try to find some kind of a routine. Like I know they had to, I feel like they were just put in this job, brand new. The whole department started over.

Somebody retired and it all started anew. Who's going to do math and science? Who's going to do language arts and social studies? And once they, it probably was organized and all that and getting them into, and then working with the regular ed teacher and trying to get them to cooperate by giving them their lesson plans. I don't think the regular ed teacher realizes how much paperwork and how much accountability they have to have.

JV: Could you describe the elements of the induction program that you feel are the most important?

M2: Be more specific.

JV: Um, I guess from interviewing the other participants it seems the induction program in this county deals with mentoring, PLC meetings, things of that nature. Maybe if you could pick out the parts you believe are the most important.

M2: Well I think the chance with us having the PLC meeting when we actually get to sit down, and it's not always to talk about a specific student. But, are they following the law? I just feel like they're just, I'm probably not answering your questions very well.

JV: You are doing fine.

M2: I just feel they've been overwhelmed, and you try to help them sort out what is a priority and what isn't. They can only do so much, and I think they're taking classes, coaching, they have their own personal lives. Any yet, whey you are here you have to be, it's a $24 / 7$ job.

JV: How are Mentors assigned in this district?

M2: I asked to be one because I taught special ed, way back when. And when, so, I thought it would be a good thing for me to do because they started this as basically a 
brand new department. Even though it was a lifetime ago and it was quite a different ballgame, I was familiar enough with what they had to do to deal with I might be able to help them out or support them.

JV: What are the characteristics of an effective Mentor?

M2: Um, somebody who can lead them, can find the answers to the questions that they have, um will be very supportive, be a liaison.

JV: What skills should a Mentor have?

M2: Have to be somebody with empathy, not just for the teacher but for the student. They do need to be a leader. Uh, they need to get the job done. They have to be pretty organized.

JV: When you mentioned being organized as a Mentor, what are you referring to? Could you go into more detail?

M2: Because they just stepped into a brand new world. So they need someone to say ok, IEP's are due then, these are triannuals, this is testing, this is benchmark. Someone who's been through the system who can put those things in order so they don't feel so bombarded.

JV: How many teachers have you mentored?

M2: Just two, this is the first time I've done it.

JV: One special education teacher and one general education teacher?

M2: Well now I do, she was in special ed. We've had a mix up of teachers, I'm still her Mentor but she's made the transition from special education to regular education.

JV: Do you think that the induction program and the provided supports would increase a special educator's chances of staying in the field?

M2: I think the support from Dr. Haines will help them. Like I said if there's something that's not right she comes up with the solution. Does that make sense to you?

JV: Yes it does.

M2: Probably the thing I worry about most with them is burnout. Because, they don't have time, there is so much to do and not enough time. We generally meet during their PLC, and that's kind of when I catch up with where they're at. Like right now they have an IEP going, then they have to go back to their class, then they have to follow so and so to resource. It's just, I think Dr. Haines is real important to keeping them here. I don't know about the burnout rate. I think it's high. You better truly be dedicated. My friend 
that retired she was truly dedicated. It takes a very special person to do that long term. My eight years that I did it, that was long enough. We had 25 kids, no LD, no MI, they were all together. They didn't give you materials. We gave one test. We gave a RAT test. I don't know if you've ever heard of it.

JV: No

M2: That's how old it is. We had to get our own materials. They were pretty much self contained so now they're just thrust out there. 


\section{Triad 1 Administrator Interview}

Jeremy Vittek: Could you describe the supports provided for the beginning teachers?

Administrator: In the school or county?

JV: County

Administrator: In the county there's a new teacher mentee program that they go through. They meet with Dr. Jones and (Special Education Coordinator) and other people throughout the year. In the school they are assigned with a senior teacher who kind of guides them through their process of being a first year teacher. Everyone, those two people meet with the principal.

JV: Could you describe how you think these supports help the teachers get acclimated in their first year?

A1: I think they just give the teachers almost like another voice, you know. If they're nervous about being a first year teacher and not knowing what to do somebody actually takes them under their wing. Somebody shows them the guidelines and the ropes and how we do things and the culture of the school. Then when they meet with the county they show them the culture of the county and what's acceptable and what's not. Unfortunately a lot of people still need to know things like that. How to dress how to behave, protocol.

JV: Could you describe some of the stressors beginning special educators face?

A1: I don't think they always know what they're getting into. I think special ed is very uh, very touchy. You know, you either love special ed or you don't. If you love it, you will want to do it and go into it. Some people go into special ed to bid out. So I think, I don't think, I don't always think that college offers the whole real world scenario. I know they're doing better letting students get into the classroom more and observe more, and longer student teaching time. You really need to infuse yourself into that situation if you're going to be a special ed teacher.

JV: So you think their perceptions are off coming in?

A1: I do, with them you don't know, Every day can be a different day. You know with our MI program you just never know what's going to happen if you're going to have to restrain a kid, whatever you're going to have to do you just don't know. It's just day to day. So I think if you get a snapshot of a classroom before you actually get your own classroom and it's good and the teacher has good control when you begin you don't know about classroom management, I mean you've heard of it, somebody told you about it, but actually doing it is a different thing.

JV: Which stressors are not dealt with through induction? 
A1: The teacher induction program? I just think it's tough you know, when I got my masters to become a principal they don't teach you all this stuff. I learn day by day. I don't think anyone can tell you what's going to happen on a daily basis I think you just have to do it.

JV: Could you describe the role of the Mentor?

A1: The Mentor is there to, whatever. Whatever that new teacher will need, you know whether it's help with a lesson plan or help with a behavior plan or um, help with modifications. They're there to kind of guide them that first year.

$\mathrm{JV}$ : What do you think are the most important supports for beginning teachers?

A1: I think they need a good principal. Honestly I think they need to be able to come to the principal right off the bat. I think their Mentor teacher needs to be in the building. I'm kind of big on that. I have a new teacher here and I got to pick her Mentor between someone in our building in a different field and someone out of the building in the same field. I picked the person in the building. Just because they know what's going on, they can help them out while they're here.

JV: could you talk a little more about that decision?

A1: I think each school has a different culture. When I made that decision I knew that my uh teacher that was Mentoring my new teacher would be here and she could stop in she could meet on the fly, she could see her at lunch. It didn't have to be scheduled, you know. You didn't have to say eighth period on Friday I'm coming to observe your class. Whenever that new teacher needs help that person was here.

JV: What would it look like if you had chosen the Mentor outside of the building?

A1: It would have had to be scheduled. I'll see you ten o'clock this day for this amount of time. I know that happens, I know lots of times that occurs. I just strongly feel that person, whether it's in the field or not in the field. Someone that has enough experience has enough time in to kind of know this system. As you know education is its own system, its own business. I think it's better to have somebody here for that person.

JV: How are Mentors assigned in this district?

A1: You have to sign up to be a Mentor because they pay them. When I chose this year they gave me a list and said I had two choices, these two people could Mentor your person. So you gotta volunteer. There's Mentor training, the pay's not great, but some people enjoy working with new people.

JV: So you have some say as far as who is the Mentor? 
A1: Yes, I still meet every month with the Mentor and mentee with a list of questions. I would help clarify any questions they still had.

JV: What are the characteristics of an effective Mentor?

A1: Then you have some people who bid on Mentor jobs and don't do anything. I mean total honesty there. We just had a conversation about one the other day. I mean she's done nothing all year, they even changed the posting this year. Um, cause they had a couple people last year who didn't do what they are supposed to do. Come the end of the year they are scrambling to do all the paperwork. You have to be compassionate. You have to be straight forward, I think in education sometimes we kind of beat around the bush a little bit. I don't do that. If you ask anyone they'll tell you I just tell them straight up. You have to do what's in the best interest of the kid. So I think that every decision we make, whether it's the Mentor mentee, or what the mentee may do in his or her own classroom has to be in the best interest of the student. I think that needs to be hammered home.

JV: What skills should a Mentor have?

A1: People skills, talking skills, um they should be very tolerant of a new teacher. New teachers are fragile, you know that first year can make or break them. They may never come back if they're not guided properly. So, I think that they need to almost, I don't want to say mothering, but they need to take care of that person that first year and maybe beyond. Who knows, maybe they'll build a great rapport and become friends.

JV: How are Mentors assessed?

A1: I don't know, that's a good question. I don't assess, I just get to choose who I want I guess. Nobody's ever asked me to assess a Mentor.

JV: Could you describe the supports you and other administrators provide the Mentors?

A1: Um, I'm very encouraging. If somebody's comes at the beginning and they want to be a Mentor. I try to encourage the people that would do a good job. Um, I think as an administrator you have that ability to encourage or discourage subtly. So, um you know if somebody comes to me and says they want to do it and I know they'd be fantastic I will talk it up and tell them this is what your going to do and how great it will be. We just had a student teacher and the person she was assigned to I gave them a huge pep talk and it end up being fantastic. I said this is your opportunity you can change this girls life.

You're going to be the one she looks up to, she'll look at you for guidance so you need to make sure you come through for her. He did a wonderful job, she's going to be a great teacher.

JV: Do you think the induction program promotes retention among special educators? 
A1: I don't know. I think the program we offer at school is better than the county program. That's just my personal feelings. I just feel like sometimes those things are done because we need to have a program. Um, and those people that are running those programs haven't been a principal at a school, haven't been or seen that administrative part that those people are going to be guided with. So, I'm sure they learn some things but I don't know if they are as effective as maybe they could be, and that's my personal opinion.

JV: Do you think preparation programs prepare special educators for their first year?

A1: I don't know. I know for a while everyone was coming from college just wasn't ready in general. They just, skill set wasn't there somebody missed the boat. I'm going all the way back to how you dress when you come to a building I have substitutes I have to talk to about their dress. This is a profession, if you want to be treated like a professional you have to dress like a professional. Somebody must have heard that like you know, when you send us people they need to be ready to work. They need to do what they're supposed to. They need to have all the qualities coming out of college. I do think it's getting better. I do see, and I see those students in the school more. So, like before it was six weeks. Now I see them coming sooner, like testing the waters as a sophomore. So if they decide they hate education they didn't decide their senior year, so that's a great thing. Getting them out there seeing what's going on. Really until you do the job it's hard, you know what I mean. It's tough to know how you're going to handle all these things. They do not teach you how to handle irate parents and you know kids that are going to cuss you out or, you don't learn all that stuff. Most of that's hands on.

JV: What are your general thoughts about why special educators leave or stay in the field?

A1: Well, there are two types of people. You can either do that, you're cut out to be a special educator or you're not. It takes a special person. Honestly I don't know if I could do that everyday. I have to help when I need to help here, but I don't do it every single day. You really have to be a special person and I don't think you learn that. I don't think four years of college makes you a special educator. I think some people get into special ed because they know there's always going to be an opening and as soon as they're finished they can take their other areas and bid out into it. I really think it comes from inside, if you're going to stay. I don't think any program is going to promote you to stay in special education if you are just not that person. Also, (Special Education Coordinator) has a lot to do with it in this county. She is amazing, and provides a lot of support for the special educators. I know they communicate with her, and she is very accessible which helps in their first years when they have questions. 


\section{Triad 2 Administrator Interview}

Jeremy Vittek: Could you describe the supports that are provided for the beginning teachers at this school?

A2: The mentorship program then the county actually has a beginning teachers program, and um, as far as the exact details it should be a three year program. When I came from Ohio County I had to go through a program each year for beginning teachers. It's sort of like what we do we have a meeting each month. The first year dealt with classroom management. The next year they talk about instruction. The third year they talk about continuing ed and anything else you may need in your classroom. Also, first year teachers get observations. That's just another thing to make sure they are working towards and you know doing what we feel is correct in the classroom. Each teacher one to three years I have to observe them six times a year I have to be in the room at least half hour two time a half hour, then the third time can be more informal, maybe watching them during their prep or anything else. And basically, you know what that consists of is I go in I got a list of what to look at what there are teaching, that they have a variety of instruction, that's a huge thing. Are they organized? Professional? Are they on time? And everything like that. And each semester I have to do the evaluation, then I go down and do the evaluation on them the second semester. It's policy 5310, I'm pretty sure is what we have to follow as far as evaluation teachers. They also, it's nice being in a small school, you know, you know what's going on more. The faculty knows what's going on. There's pros and cons for being in a small school. If you are a ninth grade science teacher, or a ninth grade English teacher you're the only one here. Compared to if you're someplace like Wheeling Park, I always relate back to that cause that's where I taught before I got back here. I had six other general science teachers; I had six other ones there. So they're teaching the same material, as far as getting material and supplies. At a bigger school it's a lot easier, you know I think it will be a lot better once we go to common core standards, nationwide. All the schools are goin to common core, I think that's gonna provide teachers now that we do these PLC's, which is another support for beginning teachers because once a week we have an hour and like right now I imagine Mr. (Principal) is up there and he'll split, what we're different here is we have a middle school. So the seventh and eighth grade pull out and they talk, then the senior high. Then they split them into departments. That's where beginning teachers, um, as far as all the different electronic programs. There's a ton of them now, you got Ed Line, I mean you got to learn how to do Ed Line, you got to learn how to do Grade Quick. It's all web based stuff that you got to learn. Printing off the tests results of QED. During the PLC time, just to have other teachers it just gives them an hour where you can sit down with somebody who already knows the program.

JV: Could you describe how you think the supports help beginning teachers get acclimated in their first year.

A2: I just you know really get in the groove. I mean when you're first hired you are overwhelmed; a lot of teachers are overwhelmed. Um, and you know just helps them feel comfortable and someone shows them, for the most part, not too many teachers, unless 
they sub for several years are going to know how to take attendance, know how to put grades in grade quick, and know all the jargon now that we are throwing out. So it definitely you know as far as any observation I have I can always come and tell the teacher, hey you need to do some of this, or classroom management issues so you know it helps them improve.

JV: What do you think are the main stressors or challenges that beginning special educators face?

A2: Paperwork, I feel um this year our special ed department, we have three special ed teachers and two of them left last year. And we have one we switched her over, she's basically self-contained. We have one student who is self contained. The other teachers she was in math and she was going back to get her special ed and she was in math, now she's back in math. Now, the other special ed um, they were both there, the state came in and did a special ed audit. Those girls were scared. Needless to say they were on pins and needles, worried to death about it. Ah the good thing is that Jonelle she is the one, one of the younger ones. She's got a special ed degree and knows a lot of the paperwork, and about IEP's, it's IEP season in the Spring. But as far as getting everything to wear we didn't have too many write ups from the state. It was good for me as an administrator, to go to her because she knows all the laws and how to get the paperwork in, it's just I think that is the hardest thing for them. I was a little bit worried because I didn't think we had a seasoned veteran that was really good at special ed. Sometimes when I have a question about special ed I can run to Mr. (Teacher) who is a veteran teacher and knows a lot about it. Our county coordinator (Name) knows, and she is good with the younger teachers, she's in good communication with Jonelle. She provides the majority of all our help for special ed stuff. It came through (Special Education Coordinator).

JV: Do you think there are any of these stressors or challenges that are not dealt with through the induction supports?

A2: Um, no. I mean, you know it all depends on how you look at it. If you have a teacher that looks at stuff in a pessimistic way they, yeah they'll bring up some stuff that can't be dealt with. I mean obviously if you are an optimist, there's some frustrating thing about being a special ed teacher as far as paperwork and sometimes when kids who for instance aren't on their medication, ah I think the girls over there are ready to pull their hair out, we are dealing with that right now. We're going to have a meeting on that here pretty soon with a parent and student and sit down and talk about the release from their doctor. That's what's great about Jonelle and (Special Education Coordinator), you call them and say they got the release from their doctors here's the lady you need to get ahold of. I don't think there's any problem from what we can do, I mean we're only limited by what the state you know and that's just something you can get in and go round and round. And there's no use in it, they're not going to change.

JV: Could you describe the role of the Mentor, as you see it. 
A2: We're kind of a funny situation right now, with the Mentor we actually have. Mrs. Jackson's a Gym teacher and she's been out of special ed, but she was the most qualified to get the Mentor position. As to avoid any type of grievance or anything that's basically what we had to do. She knows that and she feels that, she said I don't know what to do sometimes. I just tell her to relax. But, I mean the role of the Mentor, we have a couple of different roles. You know, they need to give advice. They aren't there to break anything down. I mean if you do see a younger teacher, I mean hopefully, show them hey you need to get this done. Lesson plans need to be this way, what they need to do, what they need to have in. Mentor's also, as far as telling them about paperwork and all the logistics. They need to tell them, as do the administrators, how things work around here. It would be nice for the Mentor, I would like for them to put a little more pressure on the new teachers. Not pressure, but I don't know, expectations maybe a little higher. You know, which is good you know. We have a small faculty and anyone who is not pulling their weight kind of sticks out like a sore thumb.

$\mathrm{JV}$ : What kind of orientation is there at the beginning of the school year?

A2: They bring them in, the first thing is getting all their paperwork done as far as getting their employee ID, their web ID, when you first get hired in West Virginia you need your web account to get your email account. They sit down, they just start from square one and tell them about the code of conduct and they go through sexual harassment videos and other things like that. What's funny is I can't remember going through the teacher induction. It's usually at the county office.

JV: What about once they get into the schools, how do they learn the environment of the school?

A2: Smaller school like here, it's more like the Mentor can help but the administrator definitely and again PLC is what's nice. They have this time allotted when they can meet. I mean we have designated stuff they can talk about each week. They sit down and talk about (General Education Teacher)'s kids, and all the different benchmarks. We give them a list. Then they get some time where they just get some more meeting time, that's what's so great they just get time to meet with all the other teachers. I think that's where I learned more than anywhere. I think PLC's the best for new teachers, I really strongly feel PLC's is more important than anything.

JV: What does PLC stand for?

A2: Just professional learning community, my fault there are so many acronyms in education it drives me nuts. It's basically, it's you know were aren't going to call them teachers meeting, we have faculty meetings on Monday's for like ten or fifteen minutes. Everything we do during PLC is geared towards student achievement. Even if we talk about how to post grades to Ed Line on the internet for parents that's still student achievement because parents can see it, you know. And you know the fact that they get split into department, middle school goes with middle school teachers high school goes with high school teachers. During that time if they have stuff they got to do, then they got 
time where they can just, for the most part you learn more just when you can sit and talk. Uh, you know there's a certain agenda but they also have time to talk about whatever. JV: That goes into my next question. If the teachers have a specific problem they can seek help during PLC?

A2: Yeah, any current issues. That's what I put on the agenda, is current issues at the end of the PLC hour. Anything they need to ask, or anything they don't understand what is going on. If there are any students that may be a problem, or they wonder, beginning teachers are afraid just like me as an administrator last year because I didn't know how other people dealt with them. I think beginning teachers wonder is he a problem for other teachers or just me. It can give them an inkling of what is going on.

JV: What do you think are the most important supports for beginning teachers?

A2: The most important supports? Like I said, PLC's is definitely the most important um, I never been to beginning teachers academy the one we have here uh I like the one we had in Ohio County. We talked about classroom management the first year, once a month. I hope we do that and do something as good as that.

JV: Who provides that support?

A2: The county, they report down the county office once a month, and that's you know that's really important when you get down there. The other part is just us, as far as the administrators. When I get a new teacher I really need to let them know our expectations. They need to turn in lesson plans, classroom management. They need Mentors, as far as special ed goes that's just a different situation, but Mr. Morris he always Mentors the other Science teacher. Mrs. Shimmel is our librarian, and she is mentoring our new Ag teacher. And she reports to me any issues he has, or anything that she you know she definitely reports anything she told him she doesn't feel he is doing. To make sure I um you know address it.

JV: How are Mentors assigned in this district?

A2: It's supposed to be by content area. And you know, I think they get actually get paid, maybe a little stipend. It should be someone, you shoud be teaching for over it used to be five years or three years and um, they you know we post it and we bid them out. We get a new teacher we put a posting and they bid on it. What Robyn does in human resources, um director, she just looks at their content and if it's close that's how she figures out who's most qualified. She also looks at past certifications.

JV: What do you think are the characteristics of an effective Mentor?

A2: Basically someone who knows what's going on. That's what, there are several teachers here I'd love to have as Mentors. We set aside time, you know, and that's one thing I make sure I get in my Mentor meetings when we do have them. Try to see an I got to observe them to. I think it's important that administrators are part of the whole Mentor 
process. To make sure they are doing their jobs. As far as characteristics, someone in the know, I really like for them to have strong classroom management. And you know, it doesn't mean the least amount of discipline referrals in the school. Some of my better teachers have the best classroom management; they don't have a ton of discipline referrals. They're definitely not at the bottom. But I'd like to have someone that is an effective communicator. You know, and it's just uh sometimes they just have to have a knack for it. Just talking to other people and not just new hires. You know, I'd really like for them to uh you know demand a little more, not demand, but say hey look make sure you have this in, make sure you have lesson plans, don't let your k ids out of class.

JV: So the basic expectations, you think, just letting them know what they need to do...

A2: Basically answer any questions they have. It's not as much micromanaging; somehow that's a bad word in education. I mean you know, we have to let them know what we want done here.

JV: What skills should a Mentor have?

A2: Skills? Organizational skills. People skills, definitely organizational skills. I like them organized. Communication skills, be able to tell them what they need to have. They have to be motivated. I'd like them to be professional. You know, it's kind of rough, we are fortunate the Mentors we have, I don't like Mentors coming in the building fifteen minutes late in the middle of a PLC or faculty meeting. I'm not happy when that happens. Uh, you got organizational, like I said communication skills. That's probably about it. I'm sure there is more I could add.

JV: How are Mentors assessed? Is there an evaluation?

A2: Yes. There's an evaluation. I mean the administrators we'll stop by Mentor meetings. Usually they are just supposed to, I tell everyone in the building if you need me come get me. I have stuff popping up, if they need me they need to come grab me. Usually I just listen to their meetings. So we evaluate and also the county office does. Part of that is the person being Mentored, the new teacher. They get to give their opinion too. Do I see them? Sometime people have Mentors and you don't see them. I had a Mentor program, I forgot I did, last year. I had one, I saw him a couple times and when I'd go in the county office there was a guy in the county office we'd sit down with an agenda and talk about any issues I was having.

JV: You mentioned the beginning teachers get to give their opinion. Is that a form they fill out at the end?

A2: No, basically when I had to fill out the forms for administration you just had to fill out a form about what you talked about and how you thought the session went. And usually they keep that paperwork at the county. So, you know, if any teachers say we didn't do anything, and they will write that down and turn that in. 
JV: Could you describe the supports you provide the Mentors.

A2: Mentors, basically if they come and need something we just talk to them. If they need advice, definitely continuing education stuff, professional development. For them to definitely grow as professional and to gain extra knowledge. Delegating time, that' something that they need to do at the end of the school day. As far as having meetings, or sometimes we can get Mentors and beginning teachers on the common planning, it's difficult but it helps.

JV: Do you think that these supports would improve the chances that a special educator would stay in their position or in the field?

A2: Without a doubt. I mean, it's just nice, I think the strong support is just someone you can go to that has an answer, and how quick you can get that answer. That's what's good about (Special Education Coordinator). (Special Education Coordinator) is kind of hard to get on the phone. But if I email her she is good about getting back to me with an answer really quick. Because there is nothing more, because that just jams you up. I understand when you first start and you get stuck on one little thing you don't know how to do and you can't get ahold of someone to answer it, you got a whole day wasted, almost. You know, they can come over to me they can ask me and if I can't answer it for them it's frustrating that's just the most important thing another Mentor should do is you know if they don't know the answer is to try to find one. So if they know the proper channels, if you don't know the answer but can say hey I don't know but I can email someone and I'll get back to you. You know, me if I don't know something right now I can pick up the phone or email (Special Education Coordinator) and she'll get back to me.

JV: So you mentioned, getting the answers for specific questions, so for special education who would that be?

A2: (Special Education Coordinator)'s the guru. That's who we go to, we go to (Special Education Coordinator). You know last year, with these younger teachers there was one special education teacher, and I'm busy I fly around. Sometimes when they take too long and don't give me a question, they talk for fifteen minutes and I didn't get an answer. Usually with a good Mentor or like (Special Education Coordinator), even Mr. Morris, I bring him up a lot, his son was in special ed. He knows a lot of special ed law, he's like a you know, his brain is a computer when it comes to spitting out facts. I go to him and he always knows, and half the time I have to walk away and he's still talking, he knows so much. I have to deal with these girls, and (Teacher 2) she is a new one, the next person we hire when they get stuck on something the most important thing is they need an answer now, as soon as possible. 


\section{Triad 1 Observation}

Mentor1: I don't know if I threw this out of you or not. I'm a proponent of fall IEPs and you know that.

Teacher1: Yeah

M1: With the point to where yours are getting you may want to do them in the Spring because I don't know if you are going to have enough time to schedule them and get them all done. Check the dates if you think you can get them done before they are do at the beginning of next year.

T1: Ok, am I able. That week we come back from school they give us the option to use 18 hours.

M1: You can use that 18 hours for anything. Yeah. You could do IEPs in that 18 hours. You can use, that 18 hours is for anything you deem appropriate. Here's the thing, and I'm adding to my list. Um, one of the things that came out of the monitoring, hold on (cell phone call). One of the things that came out of the monitoring, teachers are no longer allowed to chair their own meetings.

T1: Well I had to change mine. I think cause (Special Education Coordinator) at first said we were able to.

M1: We were always told that.

T1: While the monitoring was going on, she was going around with them and I had to change mine. Speech is allowed now.

M1: That's not your fault; we were always told we could do that. Uh because that is why I never worried about Karen. You're gonna need to keep records of all that, cause when she turns on you you're gonna need records. Cause it will happen.

T1: I just go to my little cubbie and stay there.

M1: That's what I did at (school name), that why I went to (school name). So I could just do that. That was one of the things that came out. Although this monitoring was a complete joke. (Special Education Coordinator), CC me on an email that was sent today because they wrote on one of my IEPs. Here's the thing I read (Special Education Coordinator)'s email, I don't know what they want here to change either. They wrote me up on the accommodations on Part A. Everything that is in there is justified in her present levels. What do you want fixed here? It's all justified. Did you figure out the KET thing?

T1: Yeah

M1: Did I send you my permission slip? 
T1: Yeah.

M1: It's easy and it gives a lot of information real quick.

T1: Yeah, and I realized on Fridays I have a space of like 40 minutes I didn't realize I had cause I had planning and then lunch. So I'm going to start on Fridays and send all the permission slips home now. Each Friday I'll pull a kid.

M1: Using that permission you don't have a timeline. Like when you are testing a kid you have an 80 day timeline. If it takes you three months it takes you three month.I

T1: Did you do practice for Math day for regionals?

M1: We never did practice period. How are you doing that? When are you doing that?

T1: Well it was during my lunch. I practiced all that with Mike and he was getting all of them, but I felt like he wasn't prepared like it was my fault.

M1: No, don't worry about it.

T1: He got none right.

M1: He must have just been off that day, it happens.

T1: I know, I was just shocked.

M1: How many do you have going to regionals?

T1: I think just two.

M1: Did you ever ask (Principal) about young writers?

T1: I did and I put notes in all the teachers' mailboxes. They wanted if they had someone I wasn't already seeing they felt should participate they could send them back and no one responded. Oh yeah, I got your text about Timmy am I taking him just on Tuesday?

M1: Just take him Thursday. That was one of the reasons we did that, you and Mike need a break. I offered Steve a break and he didn't want one.

T1: I got a call from the high school asking if I wanted another home bound. I haven't called back yet, I don't know what to say.

M1: I wouldn't, I got a call too. A lot of times they call when they can't find anybody there. 
T1: So you didn’t practice for regionals?

M1: I didn't practice for any of them. Jimmy is the one that usually did the practice. I don't know if you want to ask her if she wants to practice with those two.

T1: If anyone is going to do it it will be me. Will it be the same thing as for county/

M1: A lot of it is the same. Did you get the box for it?

T1: Yeah

M1: I would copy the terms and send them home and have them study them.

T1: That's what I did, I sent home the booklet with the terms and some sample problems.

M1: One of the reasons this works between her and I is that she is in the job I left and I know the kids. Steve might need to be labeled exceptionally gifted when he gets to high school. I can see him being one of those kids with the 140 IQ who gets poor grades.

T1: Oh I know there are so many things he should have breezed through and he doesn't even get it done. He is lazy a lot of the time.

M1: I was excited about Ryan.

T1: Yeah, I missed that dynamic when he left and went to Jefferson. Those two were funny at regionals, they were bickering just like brothers. I told them they picked up right where they left off. I thought I was going to have to separate them. When we did the budgeting the one is calling the other a cheapskate because he was buying paper dolls for his kids for Christmas. How was your day today?

M1: It wasn't bad, Kimmy wasn't that bad actually. Back to Steve, I said are sure Jessica isn't going to care, I said no. She has so many irons in the fire. Terri has worked with him in the past and did homebound, she'll be fine. The other thing, when it comes to those transitioning fifth graders do not let Carrie push you around and make you think that you have to redo the whole IEP. All you need to give her is current present levels.

T1: Which would just be their overall average at the end and all that stuff.

M1: Yeah, all that stuff you saw me sit there and write that one day.

T1: Jan tried to make me do that for Johnny's IEP because the time is different.

M1: That's her responsibility.

T1: Ok, I don't have time to have another meeting. 
M1: And she knows that, yeah she knows that. She should know better, especially if she knows who your Mentor is, because I would never do it.

T1: She knows, but she may not know how much we communicate.

M1: That's a possibility there. Ok, as I'm going over this I need you to do me a favor. I need you to call Sherry, John's mom. Explain Special Olympics to her give her the updated information and let her talk to him and let her make a decision. She doesn't think he'll be interested, but let her decide. One thing you didn't realize is being my mentee you get drug into all this stuff. Special Olympics and all that stuff.

T1: It's good though I enjoy it. 
Vita

\author{
Jeremy Vittek \\ 219 Grandview Ave., Tiltonsville, OH 43963 \\ jvittek@mix.wvu.edu \\ (412)897-6844
}

\title{
EDUCATION
}

May 2012 WEST VIRGINIA UNIVERSITY

- EdD Special Education

- Graduation date of May 12, 2012

- Dissertation topic: Induction Programs/Special Education Teacher Retention

May $2010 \quad$ UNIVERSITY OF WeSt ALABAMA

Master of Education School Counseling

- $\quad 4.0 \mathrm{GPA}$

August 2009 WEST VIRGINIA UNIVERSITY

Master of Education Special Education

- Emphasis in multicategorical special education

- $4.0 \mathrm{GPA}$

May 2007

WHEELING JESUIT UNIVERSITY

Wheeling, W

- ACT Program

- Added Special Education to Certificate

December 2002 OHIO UNIVERSITY EASTERN

Baccalaureate Degree

- Middle Childhood Education

- Concentration in Language Arts and Social Studies

\section{EXPERIENCE}

2012-Present Wheeling Jesuit University

Adjunct Instructor

- Teaching PED 333

2011-2012Ｗest Virginia University

Adjunct Instructor

St. Clairsville, C

Morgantown, W

Livingston, $A$

Morgantown, W

- Taught SPED 304: Contemporary Issues in Special Education

- Prepared class lectures

- Delivered direct instruction

- Designed course activities

- Developed mid-term and final exams

2010- 2011 West Virginia University

Morgantown, W

Teaching Assistant

Morgantown, W 
- Team Taught SPED 304: Contemporary Issues in Special Education

- Prepared class lecture

- Delivered direct instruction

- Assisted in course development

- Assisted in grading and evaluations

2010- 2011 West Virginia University

Teaching Assistant

- Team Taught SPED 500: Legal/Educational Foundations: Special Education

- Prepared class lecture

- Prepared materials for synchronous and asynchronous delivery

- Delivered content utilizing Blackboard and WIMBA

- Assisted in course development

- Assisted in grading and evaluations

2010- 2011 West Virginia University

Morgantown, W

- Supervised practicum students

- Observed practicum student

- Evaluated practicum student

- Served as cooperating professional

- Served as university supervisor

2008-2010 BUCKEYE LOCAL SCHOOL DISTRICT Intervention Specialist

Morgantown, W

- Taught science class including students with CD, LD, and ED.

- Wrote, implemented, and evaluated IEP's.

- Scheduled and led IEP conferences.

2008-2009 HARRISON CENTRAL CITY SCHOOL DISTRICT

Intervention Specialist

- Taught self-contained class of ED students at the high school level.

- Conducted skill assessment and job matching

- Developed plans to assist in qualifying for the vocational school.

\section{PRESENTATIONS}

- Vittek, J., \& Lynch, J. (2011, March) The Current State of Special Education Preparation for Principals. Presented at American Council on Rural Special Education, Albuquerque, New Mexico.

- Vittek, J. (2011, May) Veteran Special Educators' Perceptions on Factors that Lead to Retention. Presented at SCFD 615 Emerging Researcher Poster Presentation, Morgantown, West Virginia

\section{PRESENTATIONS ACCEPTED}

- Vittek, J. (2011) Veteran Special Educators' Perceptions on Factors that Lead to Retention submitted to Council for Exceptional Children: Teacher Education Division National Conference, Austin, Texas

\section{SPECIALIZED TRAINING}

- TeachMe Lab, simulated learning environment

- WIMBA Live Classroom 


\section{ASSOCIATION MEMBERSHIPS}

- Council for Exceptional Children- Teacher Education Division

- American Council on Rural Special Education

\section{SKILLS AND ACTIVITIES}

- Proficient in Microsoft Word

- Strong Time Management and Collaboration Skills

- Guest Reviewer for Rural Special Education Quarterly

\section{HONORS}

- Awarded Project Fast Track Scholarship for Special Education Doctoral Program-West Virginia University

- 4.0 GPA Fall and Spring Semesters Special Education Doctoral Program WVU

- $\quad 4.0$ GPA in School Counseling Master's Program at UWA

- 4.0 GPA in Special Education Master's Program at WVU 